\title{
Effects of Azospirillum amazonense and Bacillus subtilis on high-yielding rice (cv. Ma Lam 213) cultivated on sandy loam soils of Phu Yen province, Vietnam
}

\author{
Van Thi Phuong Nhu, ${ }^{1,}$, Truong Trong Ngon ${ }^{2}$, Cao Ngoc Diep ${ }^{3}$ \\ ${ }^{1}$ Dept. Biology, Phu Yen University, Phu Yen Province, Vietnam \\ ${ }^{2}$ Dept. Molecular Biology Biotechnology, Biotechnology R\&D Institute, Can Tho University, Can Tho City, Vietnam \\ 3Dept. Microbiology Biotechnology, Biotechnology R\&D Institute, Can Tho University, Can Tho City, Vietnam \\ Email address: \\ vanphuongnhu@gmail.com (V. T. P. Nhu), ttngon@ctu.edu.vn (T. T. Ngon), cndiep@ctu.edu.vn (C. N. Diep)
}

\section{To cite this article:}

Van Thi Phuong Nhu, Truong Trong Ngon, Cao Ngoc Diep. Effects of Azospirillum amazonense and Bacillus subtilis on High-Yielding Rice (cv. Ma Lam 213) Cultivated on Sandy Loam Soils of Phu Yen Province, Vietnam. Journal of Plant Sciences. Vol. 2, No. 6, 2014 , pp. $324-333$. doi: $10.11648 /$ j.jps.20140206.20

\begin{abstract}
Two field experiments were conducted to evaluate effects of two endophytic bacterial strains (Azospirillum amazonense SHL70, Bacillus subtilisTAL4) together with different levels of inorganic nitrogen and phosphorus fertilizers on the growth and grain yield of high-yielding rice (cv. Ma Lam 213) cultivated on silty clay loam soils of Dong Hoa district and Tuy An district, Phu Yen province, Vietnam in Summer-Autumn 2014 cropping-season. The results of two field trials showed that bacterial inoculation in rice plants (either SHL70 or TAL4 and especially mixture of SHL70 and TAL4) plus $60 \mathrm{~kg}$ N and $40 \mathrm{~kg}$ $\mathrm{P}_{2} \mathrm{O}_{5} /$ ha having yield components and grain yield were not significant difference with those of rice only applying $120 \mathrm{~kg} \mathrm{~N}$ and $80 \mathrm{~kg} \mathrm{P} \mathrm{O}_{5} /$ ha without inoculation therefore both of bacteria strains provided $50 \%$ biological nitrogen and available phosphorus quantity for high-yielding rice requirement, improvement of quality grain and soil fertility of Dong Hoa district and Tuy An district, Phu Yen province.
\end{abstract}

Keywords: Azospirillum amazonense, Biological Nitrogen Fixation, Bacillus subtilis, Grain Yield, High-Yielding Rice, Phosphate Solubilization

\section{Introduction}

Rice (Oryza sativa L.) is one of the most important crops in the world and paddy soil comprise the largest anthropogenic wetland on earth [1] and chemical fertilizers, substances composed of known quantities of nitrogen, phosphorus and potassium, keep an important role in the growth and yield of crops as high-yielding rice. Nitrogen $(\mathrm{N})$ is one of the most important nutrients in plants and is a limiting in plant growth and development and available phosphorus $(\mathrm{P})$ deficiencies in many parts of the world [2] also is the limiting factor for rice growth and development especially root development, poor flowering and lack of seed etc., consequently causing degradation in quality and quantity [3].

Recently, the potential for microbes to increases nutrient availability and to enhance crop growth has garnered the attention of the researchers, and the increasing reliance on biological processes and plant interactions with microbes through 'ecological intensification' may be one of the most promising strategies to overcome these problems [4]. Bio-fertilizers containing efficient microorganisms, improve plant growth in many ways compared to synthetic fertilizers, by way of enhancing crop growth, sustainability of environment and crop productivity and efficient microbes with PGPR and endophytic bacteria have been produced as bio-fertilizer for crop production in sustainable agriculture [5].

$\mathrm{Phu}$ Yen, is one of seven coastal provinces of central Vietnam, has 57,100 ha for rice cultivation, with average grain yield (6.036 tons/ha) and rice productivity every year estimating 344,700 tons (Statistics 2012 of Ministry of Vietnam Agriculture and Rural Development) and Phu Yen province needs large amount of chemical fertilizers to produce rice productivity to involve food requirement every year. However this overuse of chemical $\mathrm{N}$ and $\mathrm{P}$ fertilizers not only is economically expensive but also itiates a cascade of large-scale environmental impacts, including threatening ecosystem sustainability around the world by causing terrestrial and aquatic eutrophication and acidification and by 
creating large hypoxic zones [6][7]. Our previous reports indicated the endophytic bacteria as Azospirillum amazonense SHL70, Bacillus subtilisTAL01 strains could produce phytohormone, promotes the growth and rice of yield and significantly reduces the required amount of soil $\mathrm{N}$ and $\mathrm{P}$ fertilizers [8][9]. The aims of this study (i) to identify the effects of two these strains on high-yielding rice, (ii) evaluate soil fertility of two these sites in Phu Yen province.

\section{Materials and Methods}

\subsection{Bacterial Strains}

Azospirillum amazonense SHL70 and Bacillus subtilis TAL01were isolated from the rice plants [8]. Two strains were stored at $4^{\circ} \mathrm{C}$ on Burk N-free agar [10] and NBRIP agar [11] and they also multipled in Burk $\mathrm{N}$-free broth medium and NBRIP broth medium during 2-3 days and population reached to over $10^{8} \mathrm{cfu} / \mathrm{ml}$.

\subsection{Plant Seeds and Paddy Soils}

The rice cultivar used was an indica (Oryza sativa L.) "Ma Lam 213", which is a common cultivar grown in Phu Yen province and it originated from Phu Yen Crop Cultivar Center. The rice seeds were immersed with warm water $\left(65-70^{\circ} \mathrm{C}\right)$ overnight, and rinsed six times in sterilized water and rice seeds already were used in two field experiments at Dong Hoa district and Tuy An district (Figure 1).
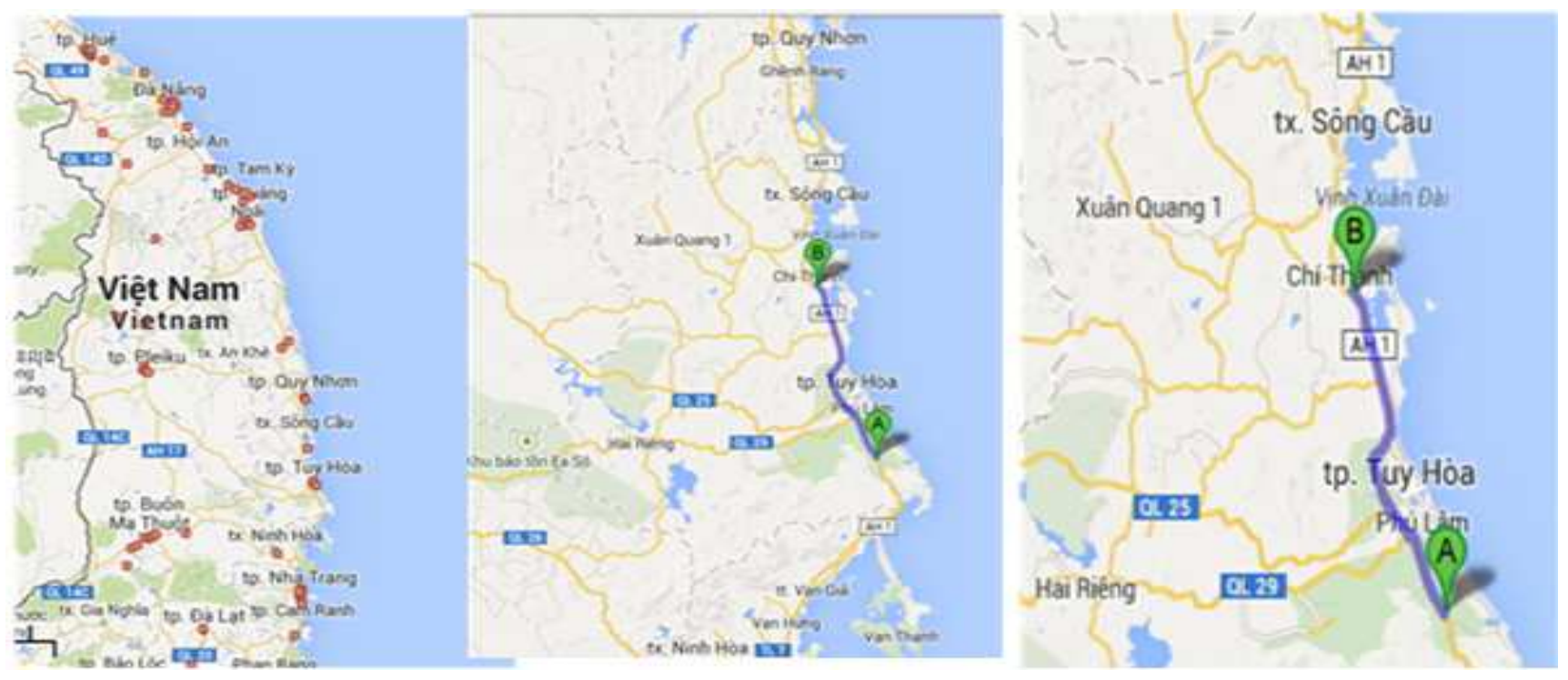

Figure 1. Two experimental sites with A (Dong Hoa dist.) and B (Tuy An dist.)

Two experimental rice fields were conducted in two sites: Dong Hoa dist. And Tuy An dist. of Phu Yen province $\left(12^{\circ} 42^{\prime} 36^{\prime \prime}\right.$ to $13^{\circ} 41^{\prime} 28^{\prime \prime} \mathrm{N}$ and from $108^{\circ} 40^{\prime} 40^{\prime \prime}$ to $\left.109^{\circ} 27^{\prime} 47^{\prime \prime E}\right)$, Vietnam from July 2014 to October 2014. The region has a typical subtropical climate with an annual precipitation of $1935 \mathrm{~mm}$ and a mean annual temperature of $29^{\circ} 8 \mathrm{C}$. The soil for the experiment was presented in Table 1.

Table 1. Chemical and physical properties of experimental soil

\begin{tabular}{|c|c|c|}
\hline Properties & Dong Hoa site values & Tuy An site values \\
\hline $\mathrm{pH}\left(\mathrm{H}_{2} \mathrm{O}\right)$ & 5.67 & 6.47 \\
\hline Organic matter $(\%)$ & 4.21 & 2.61 \\
\hline Total N (\%) & 0.225 & 0.134 \\
\hline Total P $(\%)$ & 0.072 & 0.080 \\
\hline Available P (mg $\left.100 \mathrm{~g}^{-1}\right)$ & 0.184 & 0.094 \\
\hline Exchangeable $\mathrm{K}\left(\mathrm{mg} \mathrm{kg}^{-1}\right)$ & 71.76 & 36.66 \\
\hline $\mathrm{EC}(\mathrm{mS} / \mathrm{cm})$ & 0.349 & 0.134 \\
\hline Bulk Density (kg/dm2) & 1.002 & 1.002 \\
\hline Sand $(\%)$ & 12.9 & 14.0 \\
\hline Silt $(\%)$ & 46.1 & 51.8 \\
\hline Clay $(\%)$ & 41.0 & 34.2 \\
\hline
\end{tabular}

In general, both of experimental soils are silty clay loam soil but soil fertility of Dong Hoa site is better than Tuy An one.

\subsection{Bacterial Endophyte Inoculation and Rice Cultivation}

Azospirillum amazonense SHL70 and Bacillus subtilis TAL4 were first activated in $100 \mathrm{ml}$ of Burk N-free broth medium [10] and NBRIP broth medium [11], respectively in two separated flasks $(250 \mathrm{~mL})$ for 3 days at $120 \mathrm{rpm}$ in an orbital shaker at $28^{\circ} \mathrm{C}$, after that they were transferred to $10 \mathrm{~L}$ of Burk $\mathrm{N}$-free broth medium and NBRIP broth medium in 2 big flasks (10-L) incubated in plants after 21 days sowing. For the inoculated part (A) soak the roots with $6 \mathrm{~L}$ the suspension of Azospirillum amazonense SHL70, the inoculated part (B) soak the roots with $6 \mathrm{~L}$ the suspension of Bacillus subtilis TAL04, 3 litres suspension Azospirillum amazonense SHL70 and 3 litres Bacillus subtilis TAL4 mixed each other in 10 minutes after that this mixture $(\mathrm{AB})$ soak the roots and control $(\mathrm{C})$ soaking 6 litres sterilized water. Rice root get soaked in 6 hours before transplanting with distance $15 \times 15 \mathrm{~cm}$ in the separated plots which were divided by small dikes $(40 \times 40 \mathrm{~cm})$.

Plants were regularly watered during the growing season and plant protection was done by recommendations of Phu Yen Plant Protection Service. 


\subsection{Experimental Design}

The experiment was a split-plot design with four replications with main plot (NP fertilizers with three levels: no fertilizer, $60 \mathrm{~N}-40 \mathrm{P}_{2} \mathrm{O}_{5}, 120 \mathrm{~N}-80 \mathrm{P}_{2} \mathrm{O}_{5}$ ) and subplot (bacterial strains included Azospirillum amazonense SHL70 (A), Bacillus subtilis TAL4 (B), mixture of Azospirillum amazonense SHL70 and Bacillus subtilis TAL01 (AB) and control (C)[no inoculation]).

Chemical $\mathrm{N}$ fertilizer (urea contains $46 \% \mathrm{~N}$ ) was applied in three applications: the first application was made at 10 days after sowing (DAS)(40\% of total N), the second application was performed at the tillering stage (20 DAS)(40\% of total N) and the third application at the panicle differentiation stage (35-40 DAS)(20\% total $\mathrm{N}$ ); potassium (Potassium chloride with $60 \% \mathrm{~K}_{2} \mathrm{O}$ ) the first application was made at 10 days after sowing (DAS) $(50 \%$ of total $\mathrm{K})$, the second application was performed at the tillering stage (35 DAS) $(50 \%$ of total $\mathrm{K}$ ) and Phosphorus (thermophosphate $15 \% \quad \mathrm{P}_{2} \mathrm{O}_{5}$ ) fertilizers were applied as basal dressing before transplant by broadcasting under surface soil.

\subsection{Investigation Items and Sample Collection}

Growth parameters such as plant height, panicle number per square meter, spikelet per panicle, percentage of no-seed grain, thousand grain weight were recorded at ripening stage the recommendations of Phu Yen Agriculture Extension Center.

Plant samples (rice straw and grain) were collected randomly from each treatment at the ripening stage, they were dried for analyses of biomass and of total $\mathrm{N}$ and others.

In harvesting stage, rice seeds were separated, then placed in an oven at at $70^{\circ} \mathrm{C}$ and dried at $70^{\circ} \mathrm{C}$ to a constant weight. The dry weight was recorded and the dried samples were milled to pass through a $1 \mathrm{~mm}$ screen and then stored in plastic bags for chemical analysis.

The grain yield was measured after harvesting all plants in 5 $\mathrm{m}^{2} /$ plot, grains were dried at $70^{\circ} \mathrm{C}$ and weighed when grain reached to a $14 \%$ moisture.

\subsection{Soil Sampling}

Soil samples from the plough layer $(0-20 \mathrm{~cm})$ were collected two times: before the experiment and rice harvested. Soil cores $(10-15 \mathrm{~cm})$ were randomly sampled from each plot using a soil auger after rice was harvested. These soil samples were air dried and stored in sealed glass containers at room temperature and they were transferred to Soil Analysis Laboratory,Dept. of Soil Science, Agriculture and Applied Biology College, Can Tho University to analyse $\mathrm{pH}$, total $\mathrm{N}$, available $\mathrm{P}$, exchangeable $\mathrm{K}$ and organic matter other with physical parameters.

\subsection{Statistical Analysis}

The experiment was analyzed as a two-way ANOVA with four levels of endophytes (subplot) and with three levels of chemical NP fertilizer. All analyses were conducted using the programme MSTATC, Minitab 16. The data were considered significantly different at $\mathrm{P}<0.05$.

\section{Results and Discussion}

\subsection{Effects of Two Strains on Rice at Dong Hoa Site, Phu Yen Province}

Using two endophytic bacterial strains inoculated in rice plant 21 day-old supported plant height and yield components of rice cultivated on sandy loam soil, and applied with $50 \%$ chemical fertilizers $(60 \mathrm{~N}-40 \mathrm{P})$ had the highest agronomic characteristics, this demonstrated that effects of endophytic bacteria are applying $60 \mathrm{~N}-40 \mathrm{P}$ for rice cultivation at Dong Hoa site, Phu Yen province (Table 2). Application of two endophytic bacterial strains plus $120 \mathrm{~N}-80 \mathrm{P}$ in rice cultivation had the highest grain yield however applying $120 \mathrm{~N}-80 \mathrm{P}$ only had the grain yield the same as grain yield of rice inoculated with two strains plus $60 \mathrm{~N}-40 \mathrm{P}$ treatment (Figure 3), this showed that application of chemical NP fertilizer have not responsed growth requirement of rice when it has cultivated on sandy loam soil of Dong Hoa site.

Besides, the effects of two endophytic bacterial strains and $50 \%$ chemical NP fertilizers increased the grain number/panicle and decreased no-seed ratio (\%) were presented the positive regressive between grain yield and grain number/panicle and the negative regressive between grain yield and no-seed ratio (\%) very significantly (Figure 2).
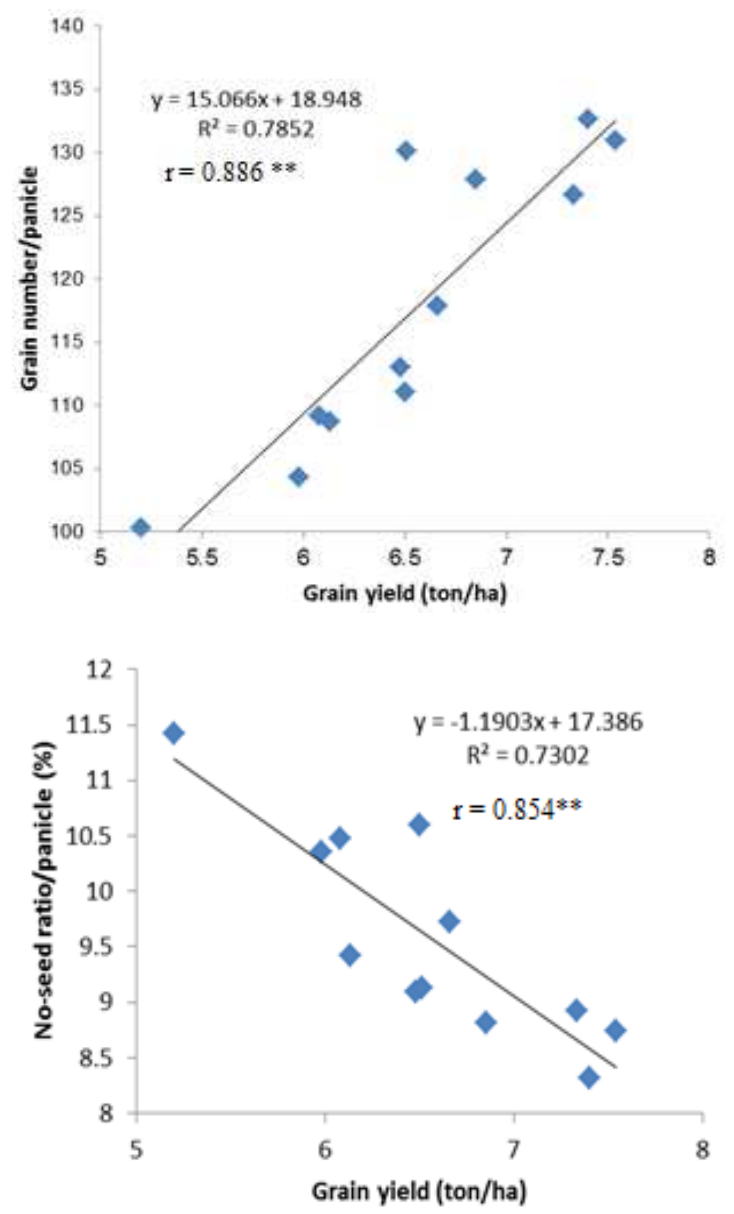

Figure 2. The correlation between grain yield (ton/ha) and grain number/panicle positively and no-seed ratio (\%) negatively in the experiment of Dong Hoa site 


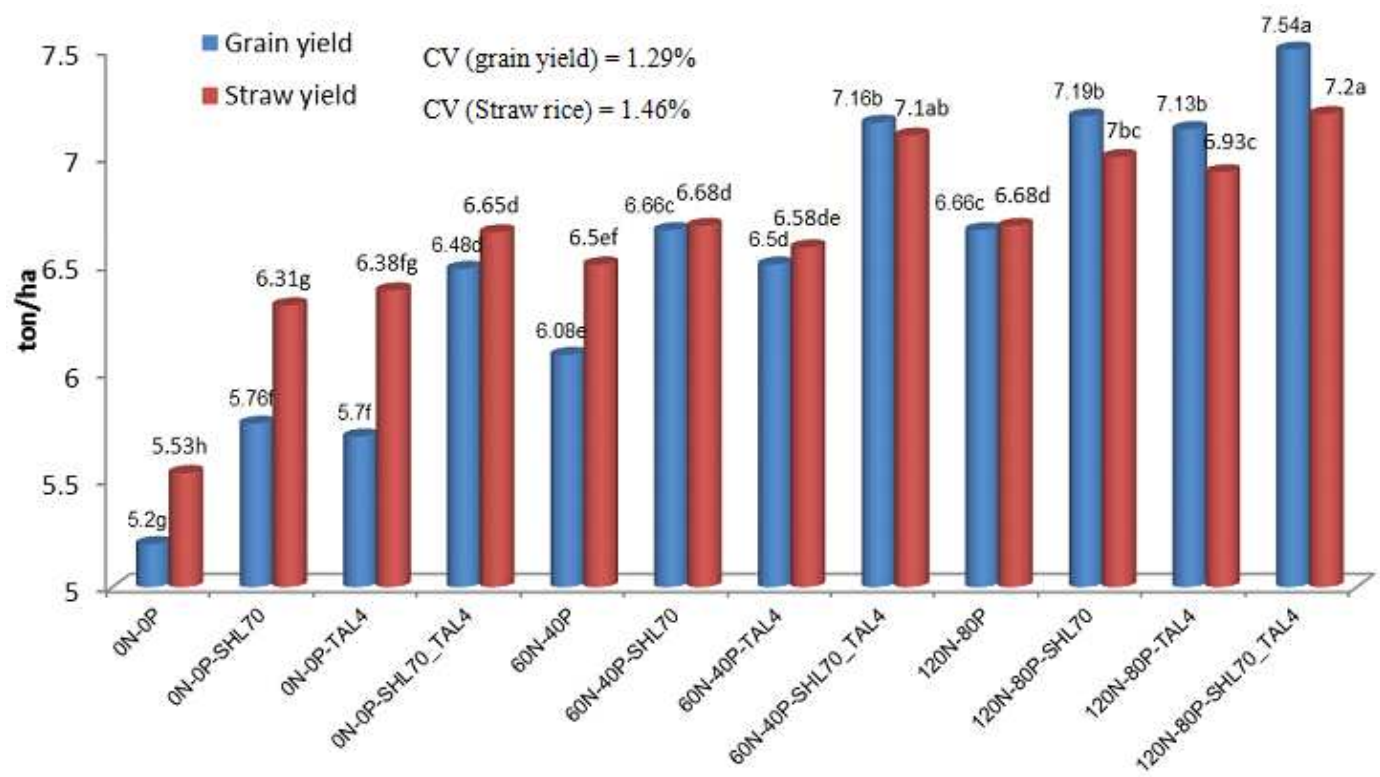

Means within a column followed by the same letter/s are not significantly different at $\mathrm{p}<0.05$

Figure 3. Effects of two endophytic bacterial strains and chemical fertilizers on grain yield and straw yield of of high-yielding rice (cv. Ma Lam 213) cultivated on sandy loam soil of Dong Hoa site, Phu Yen province, Vietnam in Autumn-Winter 2014 cropping season

Table 2. Effects of two endophytic bacterial strains and chemical fertilizerson plant height and yield components of high-yielding rice (cv. Ma Lam 213) cultivated on sandy loam soil of Dong Hoa site, Phu Yen province, Vietnam in Autumn-Winter 2014 cropping season

\begin{tabular}{|c|c|c|c|c|c|c|c|}
\hline Treatment & $\begin{array}{l}\text { Plant height } \\
(\mathrm{cm})\end{array}$ & $\begin{array}{l}\text { Panicle } \\
\text { number /tiller }\end{array}$ & $\begin{array}{l}\text { Panicle } \\
\text { number } / \mathbf{m}^{2}\end{array}$ & $\begin{array}{l}\text { Panicle length } \\
(\mathrm{cm})\end{array}$ & $\begin{array}{l}\text { Grain number } \\
\text { / panicle }\end{array}$ & $\begin{array}{l}\text { No-seed } \\
\text { ratio }(\%)\end{array}$ & $\begin{array}{l}\text { 1000- grain } \\
\text { weight (gr) }\end{array}$ \\
\hline 0N-OP-no inoculation & $85.90 \mathrm{~h}$ & $5.58 \mathrm{~h}$ & $200.7 \mathrm{~h}$ & $21.50 \mathrm{~g}$ & $100.3 \mathrm{f}$ & $11.67 \mathrm{a}$ & $23.61 \mathrm{~d}$ \\
\hline 0N-0P-SHL70 & $91.85 \mathrm{f}$ & $6.28 \mathrm{f}$ & $225.9 \mathrm{f}$ & 22.55 ef & $104.0 \mathrm{f}$ & $09.81 \mathrm{bc}$ & $24.28 \mathrm{ab}$ \\
\hline $\begin{array}{l}\text { 0N-0P-TAL4 } \\
\text { ON-0P-SH70\&TAL } 4\end{array}$ & $90.90 \mathrm{~g}$ & $6.13 \mathrm{~g}$ & $220.5 \mathrm{~g}$ & $22.20 \mathrm{f}$ & $101.8 \mathrm{f}$ & $10.59 \mathrm{~b}$ & $23.91 \mathrm{bcd}$ \\
\hline 60N-40P-no inoculation & $91.40 \mathrm{fg}$ & $6.48 \mathrm{e}$ & $233.1 \mathrm{e}$ & $22.15 \mathrm{f}$ & $109.2 \mathrm{e}$ & $10.47 \mathrm{~b}$ & $23.83 \mathrm{~cd}$ \\
\hline 60N-40P-SHL70 & $96.55 \mathrm{~b}$ & $6.90 \mathrm{~cd}$ & $248.4 \mathrm{~cd}$ & $23.58 \mathrm{c}$ & $126.2 \mathrm{c}$ & $09.11 \mathrm{cde}$ & $24.25 \mathrm{abc}$ \\
\hline 60N-40P-TAL4 & $93.95 \mathrm{e}$ & $6.83 \mathrm{~d}$ & $245.7 \mathrm{~d}$ & $23.50 \mathrm{c}$ & $122.0 \mathrm{~cd}$ & $09.73 \mathrm{bc}$ & $24.22 \mathrm{abc}$ \\
\hline 60N-40P-SHL70\&TAL4 & & & $262.8 \mathrm{a}$ & $25.53 \mathrm{a}$ & $145.4 \mathrm{a}$ & $07.83 \mathrm{f}$ & $24.37 \mathrm{a}$ \\
\hline 120N-80P-no inoculation & $92.20 \mathrm{f}$ & $6.93 \mathrm{~cd}$ & $249.3 \mathrm{~cd}$ & $23.20 \mathrm{~cd}$ & $120.1 \mathrm{~d}$ & $09.13 \mathrm{~cd}$ & $23,91 \mathrm{bcd}$ \\
\hline 120N-80P-SHL70 & $96.00 \mathrm{bc}$ & $6.98 \mathrm{bc}$ & $251.1 \mathrm{bc}$ & $25.75 \mathrm{a}$ & $135.7 \mathrm{~b}$ & $08.16 \mathrm{ef}$ & $24.44 \mathrm{a}$ \\
\hline $120 \mathrm{~N}-80 \mathrm{P}-\mathrm{TAL} 4$ & $95.15 \mathrm{~cd}$ & $7.08 \mathrm{~b}$ & $254.7 \mathrm{~b}$ & $24.45 \mathrm{~b}$ & $133.2 \mathrm{~b}$ & $08.52 \mathrm{def}$ & $24.09 \mathrm{abc}$ \\
\hline 120N-80P-SHL70\&TAL4 & 98,65 a & $7.35 \mathrm{a}$ & $264.6 \mathrm{a}$ & $25.80 \mathrm{a}$ & $143.4 \mathrm{a}$ & $08.02 \mathrm{f}$ & $24.48 \mathrm{a}$ \\
\hline F calculated & ** & ** & ** & ** & ** & ** & ** \\
\hline C.V (\%) & 0.67 & 1.49 & 1.49 & 1.53 & 2.71 & 7.18 & 1.28 \\
\hline No inoculation & $89.83 \mathrm{c}$ & $6.33 c$ & $227.7 \mathrm{c}$ & $22.28 \mathrm{c}$ & $109.9 \mathrm{c}$ & $10.42 \mathrm{a}$ & $23.78 \mathrm{c}$ \\
\hline SHL70 & $94.80 \mathrm{~b}$ & $6.72 b$ & $241.8 b$ & $23.96 a b$ & $121.9 \mathrm{~b}$ & $09.02 \mathrm{ab}$ & $24.32 \mathrm{ab}$ \\
\hline TAL4 & $93.33 \mathrm{~b}$ & $6.68 \mathrm{~b}$ & $240.3 b$ & $23.38 \mathrm{~b}$ & $119.0 \mathrm{bc}$ & $09.61 \mathrm{ab}$ & $24.07 \mathrm{~b}$ \\
\hline SHL70\&TAL4 & $97.27 \mathrm{a}$ & $7.20 \mathrm{a}$ & $259.2 \mathrm{a}$ & $24.73 \mathrm{a}$ & $135.7 \mathrm{a}$ & $08.19 \mathrm{c}$ & $24.36 \mathrm{a}$ \\
\hline F calculated & $* *$ & $* *$ & $* *$ & $* *$ & $* *$ & $* *$ & $* *$ \\
\hline C.V $(\%)$ & 2.44 & 6.20 & 6.19 & 5.07 & 10.50 & 10.85 & 1.26 \\
\hline $0 \mathrm{~N}-\mathrm{OP}$ & $90.91 b$ & $6.23 \mathrm{~b}$ & $224.3 b$ & $22.28 \mathrm{c}$ & $106.1 \mathrm{~b}$ & $10.20 \mathrm{a}$ & 24.01 \\
\hline $60 N-40 P$ & $95.01 \mathrm{a}$ & $6.88 \mathrm{a}$ & $247.5 \mathrm{a}$ & $23.69 b$ & $125.7 \mathrm{a}$ & $09.28 b$ & 24.17 \\
\hline $120 \mathrm{~N}-80 \mathrm{P}$ & $95.50 \mathrm{a}$ & $7.08 \mathrm{a}$ & $254.9 \mathrm{a}$ & $24.80 \mathrm{a}$ & $133.1 \mathrm{a}$ & $08.46 \mathrm{c}$ & 24.23 \\
\hline F calculated & ** & ** & ** & ** & $* *$ & $* *$ & n.s \\
\hline C.V (\%) & 3.08 & 5.44 & 5.43 & 4.49 & 8.70 & 11.62 & 1.53 \\
\hline
\end{tabular}

Means within a column followed by the same letter/s are not significantly different at $\mathrm{p}<0.05$

*and ** are significantly different at 0.05 and 0.01 probability respectively 
When analysis of multiple-regression among grain yield and two parameters (grain number/panicle and panicle number $/ \mathrm{m}^{2}$ ) revealed that there was a close correlation very significantly and grain number/panicle affected to grain yield strongly, the effects of two endophytic bacterial strains supported to panicle number/ $\mathrm{m}^{2}$ and grain number/panicle, this led to high grain yield.

The aquation of multiple regression as follows: $\mathrm{Y}=-1.43+$ $0.005 \mathrm{X} 1+0.030 \mathrm{X} 2$

(with $\mathrm{X} 1=$ grain number/panicle and $\mathrm{X} 2=$ panicle number $/ \mathrm{m}^{2}$ ) $\left(\mathrm{R}^{2}=0.98\right]$. This showed that panicle number $/ \mathrm{m}^{2}$ was important.

\subsection{Effects of Two Strains on Rice at Tuy an Site, Phu Yen Province}

The results of Tuy An site were the same as of Dong Hoa site, the effects of two endophytic bacterial strains plus $50 \%$ chemical fertilizers $(60 \mathrm{~N}-40 \mathrm{P})$ had the highest plant height and yield components of rice cultivated on sandy loam soil of Tuy An site, Phu Yen province (Table 3). Application of two endophytic bacterial strains plus $120 \mathrm{~N}-80 \mathrm{P}$ in rice cultivation had the highest grain yield however applying $120 \mathrm{~N}-80 \mathrm{P}$ only had the grain yield the same as grain yield of rice inoculated with two strains plus 60N-40P treatment (Figure 5), this showed that application of chemical NP fertilizer have not responsed growth requirement of rice when it has cultivated on sandy loam soil of Tuy An site.

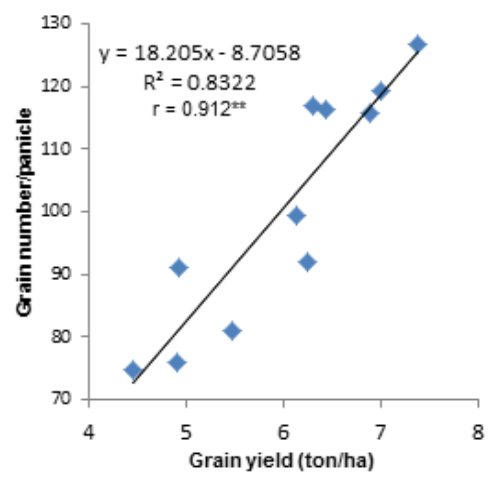

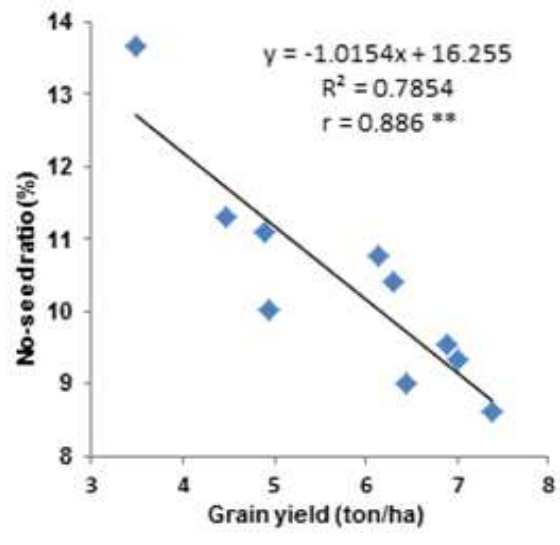

Figure 4. The correlation between grain yield (ton/ha) and grain number/panicle positively and no-seed ratio (\%) negatively in the experiment of Tuy An site

Endophytic bacterial strains affected to two parameters of yield component (grain number/panicle and no-seed ratio (\%)) as bacteria increased grain number/panicle and they reduced no-seed ratio (\%), these results were presented in Figure 4. and analysis of multiple regression between grain yield and two parameters (grain number/panicle and panicle number $/ \mathrm{m}^{2}$ ) showed that there was a close correlation very significantly and grain number/panicle affected to grain yield strongly, the effects of two endophytic bacterial strains supported to panicle number/ $\mathrm{m}^{2}$ and grain number/panicle, this led to high grain yield.

The aquation of multiple regression as follows: $\mathrm{Y}=9.06+$ $0.06 \mathrm{X} 1-0.037 \mathrm{X} 2$

(with $\mathrm{X} 1=$ grain number/panicle and $\mathrm{X} 2=$ panicle number $/ \mathrm{m}^{2}$ ) $\left(\mathrm{R}^{2}=0.87\right)$

This showed that grain number/panicle was important. and regression equation as follows:

$$
\mathrm{Y}=1673.86+47.20 \mathrm{X} 1-8.89 \mathrm{X} 2
$$

$\mathrm{Y}=\mathrm{N}$ content in soil, $\mathrm{X} 1=\mathrm{N}$ content in seed rice and $\mathrm{X} 2=$ $\mathrm{N}$ content in straw rice $\left(\mathrm{R}^{2}=0.855\right)$

Table 3. Effects of two endophytic bacterial strains and chemical fertilizers on plant height and yield components of high-yielding rice (cv. Ma Lam 213) cultivated on sandy loam soil of Tuy An site, Phu Yen province, Vietnam in Autumn-Winter 2014 cropping season

\begin{tabular}{|c|c|c|c|c|c|c|c|}
\hline Treatment & $\begin{array}{l}\text { Plant height } \\
(\mathrm{cm})\end{array}$ & $\begin{array}{l}\text { Panicle } \\
\text { number /tiller }\end{array}$ & $\begin{array}{l}\text { Panicle } \\
\text { number /m2 }\end{array}$ & $\begin{array}{l}\text { Panicle length } \\
(\mathrm{cm})\end{array}$ & $\begin{array}{l}\text { Grain number } \\
\text { / panicle }\end{array}$ & $\begin{array}{l}\text { No-seed } \\
\text { ratio }(\%)\end{array}$ & $\begin{array}{l}\text { 1000-grain } \\
\text { weight (gr) }\end{array}$ \\
\hline 0N-OP-no inoculation & $79.61 \mathrm{~g}$ & $5.83 \mathrm{i}$ & $209.7 \mathrm{i}$ & $19.44 \mathrm{f}$ & $71.65 \mathrm{f}$ & $13.66 \mathrm{a}$ & $22.54 \mathrm{~d}$ \\
\hline 0N-0P-SHL70 & $85.86 \mathrm{e}$ & $6.55 \mathrm{fg}$ & $235.8 \mathrm{fg}$ & $20.44 \mathrm{e}$ & 75.75 ef & 11.09 cde & $23.34 \mathrm{bc}$ \\
\hline ON-OP-TAL4 & $85.43 \mathrm{e}$ & $6.45 \mathrm{~g}$ & $232.2 \mathrm{~g}$ & $20.64 \mathrm{e}$ & $74.80 \mathrm{f}$ & $11.31 \mathrm{~cd}$ & $23.28 \mathrm{c}$ \\
\hline 0N-0P-SH70\&TAL4 & $89.75 \mathrm{abc}$ & $6.85 \mathrm{cde}$ & 246.6 cde & $21.75 \mathrm{e}$ & $92.13 \mathrm{~d}$ & 10.02 ef & $23.63 \mathrm{abc}$ \\
\hline $60 \mathrm{~N}-40 \mathrm{P}-$ no inoculation & $83.23 \mathrm{f}$ & $6.23 \mathrm{~h}$ & $224.1 \mathrm{~h}$ & $21.48 \mathrm{e}$ & $80.95 \mathrm{e}$ & $12.63 \mathrm{ab}$ & $23.58 \mathrm{abc}$ \\
\hline 60N-40P-SHL70 & $88.35 \mathrm{~cd}$ & $6.75 \mathrm{de}$ & $243.0 \mathrm{de}$ & $22.40 \mathrm{c}$ & $99.83 \mathrm{c}$ & $11.94 \mathrm{bc}$ & $23.89 \mathrm{abc}$ \\
\hline $60 \mathrm{~N}-40 \mathrm{P}-\mathrm{TAL} 4$ & $87.85 \mathrm{~d}$ & 6.70 ef & $241.2 \mathrm{ef}$ & $21.65 \mathrm{~d}$ & $99.30 \mathrm{c}$ & $10.77 \mathrm{de}$ & $23.93 \mathrm{ab}$ \\
\hline 60N-40P-SHL70\&TAL4 & $90.93 \mathrm{a}$ & $7.03 \mathrm{ab}$ & $252.9 \mathrm{ab}$ & $23.59 \mathrm{a}$ & $116.35 \mathrm{~b}$ & $09.00 \mathrm{fg}$ & $24.01 \mathrm{a}$ \\
\hline
\end{tabular}


329 Van Thi Phuong Nhu et al:: Effects of Azospirillum amazonense and Bacillus subtilis on High-Yielding Rice (cv. Ma Lam 213) Cultivated on Sandy Loam Soils of Phu Yen Province, Vietnam

\begin{tabular}{|c|c|c|c|c|c|c|c|}
\hline Treatment & $\begin{array}{l}\text { Plant height } \\
\text { (cm) }\end{array}$ & $\begin{array}{l}\text { Panicle } \\
\text { number /tiller }\end{array}$ & $\begin{array}{l}\text { Panicle } \\
\text { number } / \mathrm{m} 2\end{array}$ & $\begin{array}{l}\text { Panicle length } \\
(\mathrm{cm})\end{array}$ & $\begin{array}{l}\text { Grain number } \\
\text { / panicle }\end{array}$ & $\begin{array}{l}\text { No-seed } \\
\text { ratio }(\%) \\
\end{array}$ & $\begin{array}{l}\text { 1000-grain } \\
\text { weight (gr) }\end{array}$ \\
\hline 120N-80P-no inoculation & $88.85 \mathrm{bcd}$ & $6.90 \mathrm{bcd}$ & $248.4 \mathrm{bcd}$ & $21.75 \mathrm{~d}$ & $91.90 \mathrm{~d}$ & $11.87 \mathrm{bcd}$ & $23,71 \mathrm{abc}$ \\
\hline 120N-80P-SHL70 & $90.30 \mathrm{ab}$ & $6.93 \mathrm{bc}$ & $249.3 \mathrm{bc}$ & $23.00 \mathrm{~b}$ & $119.90 \mathrm{~b}$ & $09.34 \mathrm{fg}$ & $23.92 \mathrm{ab}$ \\
\hline 120N-80P-TAL4 & 90.58 a & $6.73 \mathrm{e}$ & $242.1 \mathrm{e}$ & $22,84 \mathrm{~b}$ & $115.70 \mathrm{~b}$ & $09.53 \mathrm{f}$ & $23.96 \mathrm{ab}$ \\
\hline 120N-80P-SHL70\&TAL4 & $91.23 \mathrm{a}$ & $7.10 \mathrm{a}$ & 255.6 a & $23.95 \mathrm{a}$ & $130.35 \mathrm{a}$ & $08.40 \mathrm{~g}$ & $23.94 \mathrm{ab}$ \\
\hline F calculated & $* *$ & $* *$ & $* *$ & $* *$ & $* *$ & $* *$ & $* *$ \\
\hline C.V $(\%)$ & 1.26 & 1.66 & 1.66 & 1.32 & 4.20 & 7.29 & 1.89 \\
\hline No inoculation & $82.89 \mathrm{c}$ & $6.32 \mathrm{c}$ & $227.4 \mathrm{c}$ & $20.55 \mathrm{c}$ & $81.50 \mathrm{c}$ & $12.72 \mathrm{a}$ & $23.28 \mathrm{~b}$ \\
\hline SHL70 & $88.17 \mathrm{~b}$ & $6.74 \mathrm{~b}$ & $242.7 \mathrm{~b}$ & $21.95 \mathrm{ab}$ & $98.49 \mathrm{~b}$ & $10.79 \mathrm{~b}$ & $23.72 \mathrm{ab}$ \\
\hline TAL4 & $87.95 \mathrm{~b}$ & $6.63 \mathrm{~b}$ & $238.5 \mathrm{~b}$ & $21.71 \mathrm{~b}$ & $96.60 \mathrm{~b}$ & $10.54 \mathrm{~b}$ & $23.72 \mathrm{ab}$ \\
\hline SHL70\&TAL4 & $90.63 \mathrm{a}$ & $6.99 \mathrm{a}$ & $251.7 \mathrm{a}$ & $22.76 \mathrm{a}$ & $112.94 \mathrm{a}$ & $9.14 \mathrm{c}$ & $23.86 \mathrm{a}$ \\
\hline F calculated & $* *$ & $* *$ & $* *$ & $* *$ & $* *$ & $* *$ & $* *$ \\
\hline C.V (\%) & 3.05 & 4.17 & 4.61 & 5.48 & 16.75 & 10.35 & 2.28 \\
\hline ON-OP & $85.16 \mathrm{c}$ & $6.42 \mathrm{c}$ & $231.1 \mathrm{c}$ & $20.32 \mathrm{c}$ & $78.58 \mathrm{c}$ & $11.52 \mathrm{a}$ & $23.20 \mathrm{~b}$ \\
\hline $60 N-40 P$ & $87.59 \mathrm{~b}$ & $6.68 \mathrm{~b}$ & $240.3 b$ & $22.03 \mathrm{~b}$ & $99.11 \mathrm{~b}$ & $11.08 \mathrm{a}$ & $23.85 \mathrm{a}$ \\
\hline $120 \mathrm{~N}-80 \mathrm{P}$ & $90.24 \mathrm{a}$ & $6.91 \mathrm{a}$ & $248.9 \mathrm{a}$ & $22.88 \mathrm{a}$ & $114.46 \mathrm{a}$ & $09.78 \mathrm{~b}$ & $23.88 \mathrm{a}$ \\
\hline F calculated & $* *$ & $* *$ & $* *$ & $* *$ & $* *$ & $* *$ & $* *$ \\
\hline C.V (\%) & 3.36 & 4.62 & 4.62 & 4.20 & 13.07 & 14.25 & 2.03 \\
\hline
\end{tabular}

Means within a column followed by the same letter/s are not significantly different at $\mathrm{p}<0.05$ *and ** are significantly different at 0.05 and 0.01 probability respectively

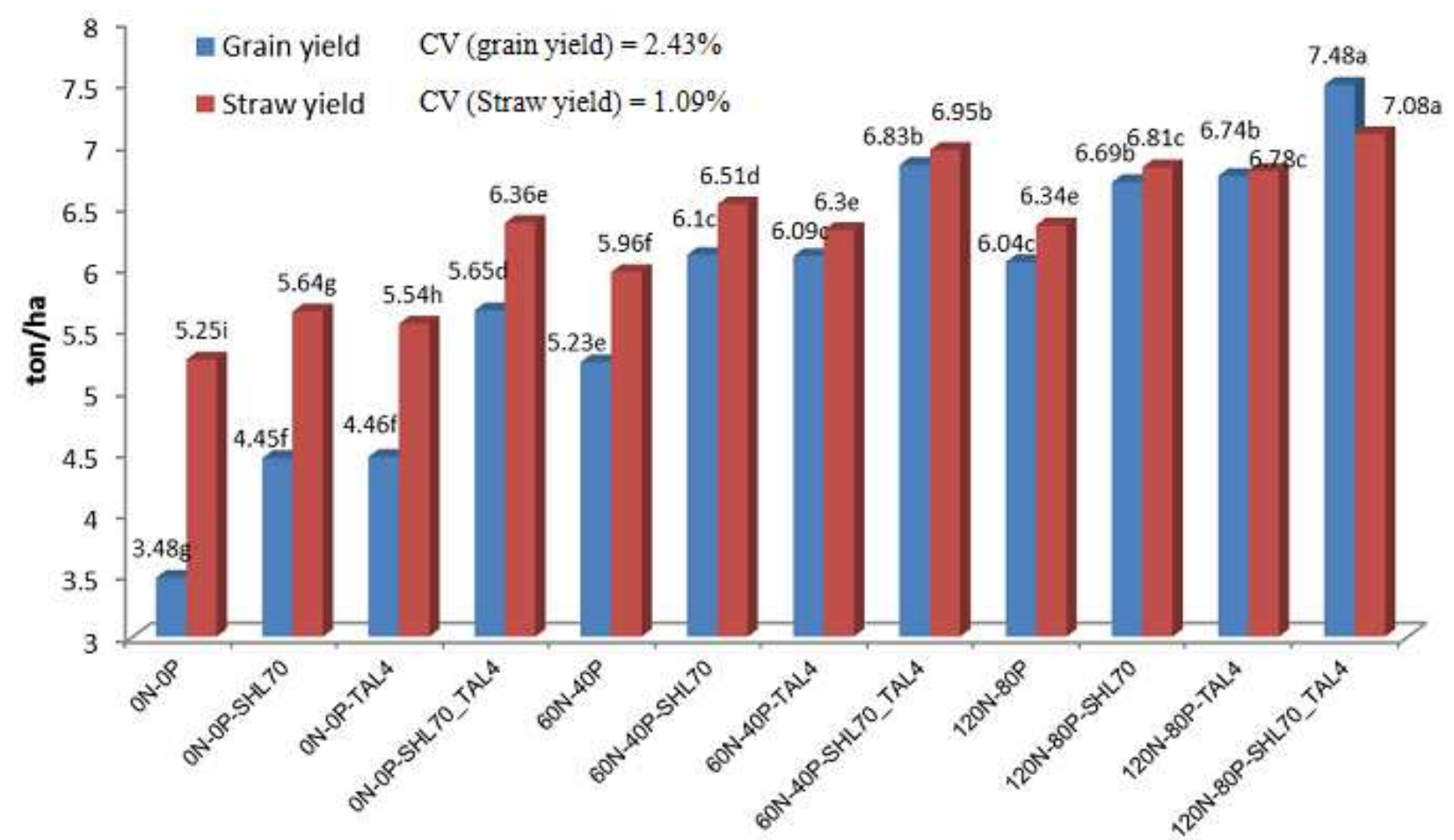

Means within a column followed by the same letter/s are not significantly different at $\mathrm{p}<0.05$

Figure 5. Effects of two endophytic bacterial strains and chemical fertilizers on grain yield of of high-yielding rice (cv. Ma Lam 213) cultivated on sandy loam soil of Tuy An site, Phu Yen province, Vietnam in Autumn-Winter 2014 cropping season 
Table 4. Effects of endophytic bacteria and chemical fertilizers on $N$ contents of rice straw, rice seed and soil of Dong Hoa site

\begin{tabular}{|c|c|c|c|c|c|c|c|c|c|}
\hline Treatment & $\begin{array}{l}\text { Seed rice } \\
\text { Yield } \\
(\mathrm{kg} / \mathrm{ha})^{+}\end{array}$ & $\begin{array}{l}\mathrm{N} \text { in seed } \\
\text { rice }(\%)\end{array}$ & $\begin{array}{l}\text { Protein } \\
\text { content in seed } \\
\text { rice }(\%)\end{array}$ & $\begin{array}{l}\mathrm{N} \text { content } \\
\text { in rice } \\
\text { straw }(\%)\end{array}$ & $\begin{array}{l}\text { Total } \mathrm{N} \text { in } \\
\text { rice straw } \\
(\mathrm{kg} / \mathrm{ha})\end{array}$ & $\begin{array}{l}\text { Total } N \text { in } \\
\text { seed rice } \\
(\mathrm{kg} / \mathrm{ha})\end{array}$ & $\begin{array}{l}\text { Total protein } \\
\text { in seed rice } \\
(\mathrm{kg} / \mathrm{ha})\end{array}$ & $\begin{array}{l}N \text { content } \\
\text { In soil } \\
(\%)\end{array}$ & $\begin{array}{l}\text { Total } \mathrm{N} \text { in } \\
\text { soil } \\
\text { (kg/ha) }\end{array}$ \\
\hline ON-OP-No inoculation & $4212 \mathrm{~g}$ & $0.833 \mathrm{f}$ & $4.830 \mathrm{f}$ & $0.360 \mathrm{~g}$ & $19.92 \mathrm{~h}$ & $35.08 \mathrm{~h}$ & $203.47 \mathrm{~h}$ & $0.154 \mathrm{f}$ & $3088 \mathrm{f}$ \\
\hline 0N-0P-SHL70 & $4668 \mathrm{f}$ & $0.925 \mathrm{~d}$ & $5.367 \mathrm{~d}$ & $0.407 \mathrm{f}$ & $25.71 \mathrm{~g}$ & $43.19 \mathrm{f}$ & $250.50 \mathrm{f}$ & $0.174 \mathrm{e}$ & 3476 e \\
\hline 0N-OP-TAL4 & $4617 \mathrm{f}$ & $0.901 \mathrm{e}$ & $5.225 \mathrm{e}$ & $0.444 \mathrm{de}$ & $28.29 \mathrm{f}$ & $41.59 \mathrm{~g}$ & $241.22 \mathrm{~g}$ & $0.174 \mathrm{e}$ & $3475 \mathrm{e}$ \\
\hline 0N-0P-SHL70\&TAL4 & $5245 \mathrm{~d}$ & $0.955 \mathrm{c}$ & $5.540 \mathrm{c}$ & $0.509 \mathrm{c}$ & $33.87 \mathrm{~cd}$ & $50.09 \mathrm{~d}$ & $290.53 \mathrm{~d}$ & $0.200 \mathrm{bc}$ & $4003 \mathrm{bc}$ \\
\hline $60 \mathrm{~N}-40 \mathrm{P}-\mathrm{No}$ inoculation & $4921 \mathrm{e}$ & $0.906 \mathrm{e}$ & $5.257 \mathrm{e}$ & $0.438 \mathrm{e}$ & $28.45 \mathrm{f}$ & $44.60 \mathrm{e}$ & $258.69 \mathrm{e}$ & $0.175 \mathrm{e}$ & $3491 \mathrm{e}$ \\
\hline 60N-40P-TAL4 & $5265 \mathrm{~d}$ & $0.958 \mathrm{c}$ & $5.555 \mathrm{c}$ & $0.462 \mathrm{~d}$ & $30.40 \mathrm{e}$ & $50.43 \mathrm{~cd}$ & $292.49 \mathrm{~cd}$ & $0.190 \mathrm{~d}$ & $3810 \mathrm{~d}$ \\
\hline 60N-40P-SHL70\&TAL4 & $5802 \mathrm{~b}$ & $0.979 \mathrm{ab}$ & $5.678 \mathrm{ab}$ & $0.588 \mathrm{a}$ & $41.79 \mathrm{a}$ & $56.80 \mathrm{~b}$ & $329.42 \mathrm{~b}$ & $0.192 \mathrm{~cd}$ & $3834 \mathrm{~cd}$ \\
\hline $120 \mathrm{~N}-80 \mathrm{P}-\mathrm{No}$ inoculation & $5397 \mathrm{c}$ & $0.932 \mathrm{~d}$ & $5.407 \mathrm{~d}$ & $0.453 \mathrm{de}$ & $30.21 \mathrm{e}$ & $50.30 \mathrm{~cd}$ & $291.75 \mathrm{~cd}$ & $0.181 \mathrm{e}$ & $3622 \mathrm{e}$ \\
\hline 120N-80P-SHL70 & $5822 \mathrm{~b}$ & $0.959 \mathrm{c}$ & $5.560 \mathrm{c}$ & $0.537 \mathrm{~b}$ & $37.55 \mathrm{~b}$ & $55.81 \mathrm{~b}$ & $323.67 \mathrm{~b}$ & $0.193 \mathrm{~cd}$ & $3850 \mathrm{~cd}$ \\
\hline $120 \mathrm{~N}-80 \mathrm{P}-\mathrm{TAL} 4$ & $5771 \mathrm{~b}$ & $0.966 \mathrm{bc}$ & $5.605 \mathrm{bc}$ & $0.506 \mathrm{c}$ & $35.01 \mathrm{c}$ & $55.77 \mathrm{~b}$ & $323.43 \mathrm{~b}$ & $0.204 \mathrm{ab}$ & $4089 \mathrm{ab}$ \\
\hline $\begin{array}{l}\text { 120N-80P-SHL70\&TAL4 } \\
\text { Calculated F }\end{array}$ & $\begin{array}{l}6105 \mathrm{a} \\
* *\end{array}$ & $\begin{array}{l}0.986 \mathrm{a} \\
* *\end{array}$ & $\begin{array}{l}5.719 \mathrm{a} \\
* *\end{array}$ & $\begin{array}{l}0.539 \mathrm{~b} \\
* *\end{array}$ & $\begin{array}{l}38.80 \mathrm{~b} \\
* *\end{array}$ & $\begin{array}{l}60.20 \mathrm{a} \\
* *\end{array}$ & $\begin{array}{l}349.17 \text { a } \\
* *\end{array}$ & $\begin{array}{l}0.212 \mathrm{a} \\
* *\end{array}$ & $\begin{array}{l}4246 \mathrm{a} \\
* *\end{array}$ \\
\hline C.V $(\%)$ & 1.29 & 1.35 & 1.35 & 3.06 & 8.25 & 1.82 & 1.85 & 3.22 & 3.23 \\
\hline SHL70 & $5295 \mathrm{~b}$ & $0.947 \mathrm{~b}$ & $5.490 \mathrm{~b}$ & $0.478 \mathrm{~b}$ & $31.98 \mathrm{~b}$ & $50.19 \mathrm{~b}$ & $291.13 \mathrm{~b}$ & $0.185 \mathrm{~b}$ & $3710 \mathrm{~b}$ \\
\hline TAL4 & $5218 \mathrm{bc}$ & $0.942 \mathrm{~b}$ & $5.462 \mathrm{~b}$ & $0.471 \mathrm{~b}$ & $31.23 \mathrm{~b}$ & $49.26 \mathrm{~b}$ & $285.71 \mathrm{~b}$ & $0.190 \mathrm{~b}$ & $3791 \mathrm{~b}$ \\
\hline SHL70\&TAL4 & $5717 \mathrm{a}$ & $0.973 \mathrm{a}$ & $5.646 \mathrm{a}$ & $0.546 \mathrm{a}$ & $38.15 \mathrm{a}$ & $55.70 \mathrm{a}$ & $323.04 \mathrm{a}$ & $0.201 \mathrm{a}$ & 4028 a \\
\hline Calculated F & $* *$ & $* *$ & $* *$ & $* *$ & $* *$ & $* *$ & $* *$ & $* *$ & $* *$ \\
\hline C.V $(\%)$ & 9.02 & 3.30 & 3.30 & 9.05 & 13.3 & 11.59 & 11.59 & 6.48 & 6.48 \\
\hline $\mathrm{ON}-\mathrm{OP}$ & $4685 \mathrm{c}$ & $0.903 \mathrm{~b}$ & $5.240 \mathrm{~b}$ & $0.430 \mathrm{~b}$ & $26.95 \mathrm{~b}$ & $42.49 \mathrm{c}$ & $246.43 \mathrm{c}$ & $0.176 \mathrm{c}$ & $3511 \mathrm{c}$ \\
\hline $60 N-40 P$ & $5346 \mathrm{~b}$ & $0.950 \mathrm{a}$ & $5.509 \mathrm{a}$ & $0.495 \mathrm{a}$ & $33.33 \mathrm{a}$ & $50.85 \mathrm{~b}$ & $294.95 b$ & $0.187 \mathrm{~b}$ & $3734 \mathrm{~b}$ \\
\hline $120 \mathrm{~N}-80 \mathrm{P}$ & 5774 a & $0.961 \mathrm{a}$ & $5.573 \mathrm{a}$ & $0.508 \mathrm{a}$ & $35.39 \mathrm{a}$ & $55.52 \mathrm{a}$ & $322.01 \mathrm{a}$ & $0.198 \mathrm{a}$ & 3952 a \\
\hline Calculated F & $* *$ & $* *$ & $* *$ & $* *$ & $* *$ & $* *$ & $* *$ & $* *$ & $* *$ \\
\hline C.V $(\%)$ & 6.29 & 5.29 & 3.75 & 11.12 & 15.04 & 9.43 & 9.42 & 7.41 & 7.40 \\
\hline
\end{tabular}

${ }^{+}$Seed yield $=$grain yield $\mathrm{x} 0.81$

Means within a column followed by the same letter/s are not significantly different at $\mathrm{p}<0.05$

*and ** are significantly different at 0.05 and 0.01 probability respectively

Table 5. Effects of endophytic bacteria and chemical fertilizers on P contents of rice straw, rice seed and soil of Dong Hoa site

\begin{tabular}{|c|c|c|c|c|c|c|c|c|}
\hline Treatment & $\begin{array}{l}\text { Seed rice } \\
\text { Yield } \\
(\mathrm{kg} / \mathrm{ha})^{+}\end{array}$ & $\begin{array}{l}P \text { in seed } \\
\text { rice }(\%)\end{array}$ & $\begin{array}{l}P \text { content in } \\
\text { rice straw } \\
(\%)\end{array}$ & $\begin{array}{l}\text { Total } P \text { in } \\
\text { rice straw } \\
(\mathrm{kg} / \mathrm{ha})\end{array}$ & $\begin{array}{l}\text { Total } P \text { in } \\
\text { seed rice } \\
(\mathrm{kg} / \mathrm{ha})\end{array}$ & $\begin{array}{l}\text { Total P in } \\
\text { plant rice } \text { r }^{++} \\
(\mathrm{kg} / \mathrm{ha})\end{array}$ & $\begin{array}{l}\text { P content } \\
\text { In soil } \\
(\mathrm{mg} / \mathrm{kg})\end{array}$ & $\begin{array}{l}\text { Total P in } \\
\text { soil (kg/ha) }\end{array}$ \\
\hline 0N-OP-No inoculation & $4212 \mathrm{~g}$ & $0.222 \mathrm{i}$ & $0.063 \mathrm{f}$ & $3.496 \mathrm{~h}$ & $9.479 \mathrm{~g}$ & $12.976 \mathrm{~g}$ & $4.163 \mathrm{j}$ & $8.327 \mathrm{j}$ \\
\hline 0N-OP-TAL4 & $4617 \mathrm{f}$ & $0.236 \mathrm{fg}$ & $0.076 \mathrm{de}$ & $4.846 \mathrm{efg}$ & $10.843 \mathrm{f}$ & $15.689 \mathrm{f}$ & $5.677 \mathrm{hi}$ & $11.353 \mathrm{hi}$ \\
\hline 0N-0P-SHL70\&TAL4 & $5245 \mathrm{~d}$ & $0.244 \mathrm{e}^{\circ}$ & $0.091 \mathrm{c}$ & $6.030 \mathrm{~d}$ & $12.765 \mathrm{e}$ & $18.796 \mathrm{~d}$ & $6.880 \mathrm{ef}$ & 13.760 ef \\
\hline $60 \mathrm{~N}-40 \mathrm{P}-\mathrm{No}$ inoculation & $4921 \mathrm{e}$ & $0.228 \mathrm{hi}$ & 0.068 ef & $4.407 \mathrm{fg}$ & $11.198 \mathrm{f}$ & $15.605 \mathrm{f}$ & $5.990 \mathrm{gh}$ & $11.980 \mathrm{gh}$ \\
\hline $60 \mathrm{~N}-40 \mathrm{P}-\mathrm{SHL} 70$ & $5397 \mathrm{c}$ & $0.240 \mathrm{ef}$ & $0.076 \mathrm{de}$ & $5.075 \mathrm{ef}$ & $12.870 \mathrm{e}$ & $17.945 \mathrm{e}$ & $6.403 \mathrm{fg}$ & $12.807 \mathrm{fg}$ \\
\hline $60 \mathrm{~N}-40 \mathrm{P}-\mathrm{TAL} 4$ & $5265 \mathrm{~d}$ & $0.253 \mathrm{~d}$ & $0.084 \mathrm{~cd}$ & $5.527 \mathrm{de}$ & $13.362 \mathrm{~d}$ & $18.889 \mathrm{~d}$ & $7.490 \mathrm{de}$ & $14.980 \mathrm{de}$ \\
\hline 60N-40P-SHL70\&TAL4 & $5802 \mathrm{~b}$ & $0.280 \mathrm{~b}$ & $0.109 \mathrm{~b}$ & $7.795 \mathrm{bc}$ & $16.203 \mathrm{~b}$ & $23.999 \mathrm{~b}$ & $8.663 \mathrm{c}$ & $17.327 \mathrm{c}$ \\
\hline $120 \mathrm{~N}-80 \mathrm{P}-\mathrm{No}$ inoculation & $5397 \mathrm{c}$ & 0.238 efg & $0.078 \mathrm{~d}$ & $5.224 \mathrm{e}$ & $12.889 \mathrm{e}$ & $18.112 \mathrm{de}$ & $8.067 \mathrm{~cd}$ & $16.133 \mathrm{~cd}$ \\
\hline $120 \mathrm{~N}-80 \mathrm{P}-\mathrm{SHL} 70$ & $5822 \mathrm{~b}$ & $0.226 \mathrm{c}$ & $0.105 \mathrm{~b}$ & $7.297 \mathrm{c}$ & $15.466 \mathrm{c}$ & $22.763 \mathrm{c}$ & $9.613 \mathrm{~b}$ & $19.227 \mathrm{~b}$ \\
\hline 120N-80P-TAL4 & $5771 \mathrm{~b}$ & $0.277 \mathrm{~b}$ & $0.120 \mathrm{a}$ & $8.285 \mathrm{~b}$ & $15.958 \mathrm{~b}$ & $24.243 \mathrm{~b}$ & $10.267 \mathrm{~b}$ & $20.533 b$ \\
\hline $120 \mathrm{~N}-80 \mathrm{P}-\mathrm{SHL} 70 \& \mathrm{TAL} 4$ & $6105 \mathrm{a}$ & $0.302 \mathrm{a}$ & $0.127 \mathrm{a}$ & $9.212 \mathrm{a}$ & $18.453 \mathrm{a}$ & $27.665 \mathrm{a}$ & $11.633 \mathrm{a}$ & $23.267 \mathrm{a}$ \\
\hline Calculated F & $* *$ & $* *$ & $* *$ & $* *$ & $* *$ & $* *$ & $* *$ & $* *$ \\
\hline C.V $(\%)$ & 1.29 & 1.73 & 5.95 & 6.92 & 1.84 & 2.54 & 5.47 & 5.46 \\
\hline SHL70 & $5295 \mathrm{~b}$ & $0.246 \mathrm{bc}$ & $0.083 \mathrm{bc}$ & $5.548 \mathrm{bc}$ & $13.062 \mathrm{bc}$ & $18.610 \mathrm{bc}$ & $7.037 \mathrm{~b}$ & $14.073 \mathrm{~b}$ \\
\hline TAL4 & $5218 \mathrm{bc}$ & $0.255 \mathrm{~b}$ & $0.093 \mathrm{~b}$ & $6.219 \mathrm{~b}$ & $13.388 \mathrm{~b}$ & $19.607 \mathrm{~b}$ & $7.811 \mathrm{ab}$ & $15.622 \mathrm{ab}$ \\
\hline SHL70\&TAL4 & $5717 \mathrm{a}$ & $0.275 \mathrm{a}$ & $0.109 \mathrm{a}$ & $7.679 \mathrm{a}$ & $15.807 \mathrm{a}$ & $23.486 \mathrm{a}$ & $9.059 \mathrm{a}$ & $18.118 \mathrm{a}$ \\
\hline Calculated F & $* *$ & $* *$ & $* *$ & $* *$ & $* *$ & $* *$ & $*$ & $* *$ \\
\hline C.V $(\%)$ & 9.02 & 7.26 & 18.33 & 22.7 & 11.57 & 17.48 & 26.48 & 26.52 \\
\hline ON-OP & $4685 \mathrm{c}$ & $0.233 \mathrm{c}$ & $0.075 \mathrm{~b}$ & $4.661 \mathrm{~b}$ & $10.984 \mathrm{c}$ & $15.646 \mathrm{c}$ & $5.453 \mathrm{c}$ & $10.907 \mathrm{c}$ \\
\hline $60 \mathrm{~N}-40 \mathrm{P}$ & $5346 \mathrm{~b}$ & $0.250 \mathrm{~b}$ & $0.084 \mathrm{~b}$ & $5.701 \mathrm{~b}$ & $13.408 \mathrm{~b}$ & $19.109 \mathrm{~b}$ & $7.173 b$ & $14.273 \mathrm{~b}$ \\
\hline $120 \mathrm{~N}-80 \mathrm{P}$ & $5774 \mathrm{a}$ & $0.271 \mathrm{a}$ & $0.108 \mathrm{a}$ & $7.504 \mathrm{a}$ & $15.691 \mathrm{a}$ & $23.196 \mathrm{a}$ & $9.895 \mathrm{a}$ & $19.790 \mathrm{a}$ \\
\hline Calculated F & $* *$ & $* *$ & $* *$ & $* *$ & $* *$ & $* *$ & $* *$ & $* *$ \\
\hline C.V $(\%)$ & 6.29 & 7.62 & 18.70 & 22.64 & 13.26 & 15.91 & 16.12 & 16.15 \\
\hline
\end{tabular}

${ }^{+}$Seed yield $=$grain yield $\mathrm{x} 0.81$

${ }^{++} \mathrm{P}$ in seed and $\mathrm{P}$ in straw rice; Means within a column followed by the same letter/s are not significantly different at $\mathrm{p}<0.05$

$*$ and $* *$ are significantly different at 0.05 and 0.01 probability respectively 
331 Van Thi Phuong Nhu et al.: Effects of Azospirillum amazonense and Bacillus subtilis on High-Yielding Rice (cv. Ma Lam 213)

Cultivated on Sandy Loam Soils of Phu Yen Province, Vietnam

Table 6. Effects of endophytic bacteria and chemical fertilizers on $N$ contents of rice straw, rice seed and soil of Tuy An site

\begin{tabular}{|c|c|c|c|c|c|c|c|c|c|}
\hline Treatment & $\begin{array}{l}\text { Seed rice } \\
\text { Yield } \\
\text { (kg/ha) }^{+}\end{array}$ & $\begin{array}{l}N \text { content } \\
\text { in seed rice } \\
(\%)\end{array}$ & $\begin{array}{l}\text { Protein } \\
\text { content in } \\
\text { seed rice } \\
(\%)\end{array}$ & $\begin{array}{l}\mathrm{N} \text { content } \\
\text { in rice } \\
\text { straw }(\%)\end{array}$ & $\begin{array}{l}\text { Total } N \text { in } \\
\text { rice straw } \\
(\mathrm{kg} / \mathrm{ha})\end{array}$ & $\begin{array}{l}\text { Total } N \text { in } \\
\text { seed rice } \\
(\mathrm{kg} / \mathrm{ha})\end{array}$ & $\begin{array}{l}\text { Total } \\
\text { protein in } \\
\text { seed rice } \\
(\mathrm{kg} / \mathrm{ha})\end{array}$ & $\begin{array}{l}N \text { content } \\
\text { in soil } \\
(\%)\end{array}$ & $\begin{array}{l}\text { Total } N \text { in } \\
\text { soil } \\
\text { (kg/ha) }\end{array}$ \\
\hline 0N-OP-No inoculation & $2815 \mathrm{~g}$ & $0.764 \mathrm{~g}$ & $4.431 \mathrm{~g}$ & $0.371 \mathrm{~h}$ & $19.50 \mathrm{~g}$ & $21.50 \mathrm{i}$ & $124.71 \mathrm{i}$ & $0.101 \mathrm{~g}$ & $2028 \mathrm{~g}$ \\
\hline 0N-0P-SHL70 & $3905 \mathrm{f}$ & $0.853 \mathrm{e}$ & $4.948 \mathrm{e}$ & $0.429 \mathrm{~g}$ & $24.19 \mathrm{f}$ & $30.75 \mathrm{~g}$ & $178.32 \mathrm{~g}$ & $0.121 \mathrm{e}$ & $2412 \mathrm{e}$ \\
\hline ON-OP-TAL4 & $3615 \mathrm{f}$ & $0.806 \mathrm{f}$ & $4.676 \mathrm{f}$ & $0.453 \mathrm{f}$ & $25.09 \mathrm{f}$ & $29.13 \mathrm{~h}$ & $168.98 \mathrm{~h}$ & $0.126 \mathrm{~d}$ & $2520 \mathrm{~d}$ \\
\hline 0N-0P-SHL70\&TAL4 & $4577 \mathrm{~d}$ & $0.943 \mathrm{~cd}$ & $5.471 \mathrm{~cd}$ & $0.531 \mathrm{~cd}$ & $33.75 \mathrm{~d}$ & $43.16 \mathrm{e}$ & $250.35 \mathrm{e}$ & $0.134 \mathrm{c}$ & $2687 \mathrm{c}$ \\
\hline $60 \mathrm{~N}-40 \mathrm{P}-\mathrm{No}$ inoculation & $4232 \mathrm{e}$ & 0.838 ef & $4.861 \mathrm{ef}$ & $0.479 \mathrm{e}$ & $28.57 \mathrm{e}$ & $35.37 \mathrm{f}$ & $205.15 \mathrm{f}$ & $0.113 \mathrm{f}$ & $2266 \mathrm{f}$ \\
\hline 60N-40P-SHL70 & $4941 \mathrm{c}$ & $0.913 \mathrm{~d}$ & $5.293 \mathrm{~d}$ & $0.542 \mathrm{c}$ & $35.32 \mathrm{c}$ & $45.09 \mathrm{~d}$ & $261.52 \mathrm{~d}$ & $0.123 \mathrm{de}$ & $2452 \mathrm{de}$ \\
\hline 60N-40P-TAL4 & $4931 \mathrm{c}$ & $0.939 \mathrm{~cd}$ & $5.449 \mathrm{~cd}$ & $0.513 \mathrm{~d}$ & $32.32 \mathrm{~d}$ & $46.31 \mathrm{~d}$ & $268.62 \mathrm{~d}$ & $0.125 \mathrm{de}$ & $2504 \mathrm{de}$ \\
\hline 60N-40P-SHL70\&TAL4 & $5528 \mathrm{~b}$ & $1.072 \mathrm{~b}$ & $6.219 \mathrm{~b}$ & $0.587 \mathrm{~b}$ & $40.78 \mathrm{~b}$ & $59.26 \mathrm{bc}$ & $343.73 \mathrm{bc}$ & $0.145 \mathrm{~b}$ & $2898 \mathrm{~b}$ \\
\hline $120 \mathrm{~N}-80 \mathrm{P}-\mathrm{No}$ inoculation & $4890 \mathrm{c}$ & $0.991 \mathrm{c}$ & $5.515 \mathrm{c}$ & 0.471 ef & $29.82 \mathrm{e}$ & $46.50 \mathrm{~d}$ & $269.68 \mathrm{~d}$ & $0.135 \mathrm{c}$ & $2698 \mathrm{c}$ \\
\hline 120N-80P-SHL70 & $5417 \mathrm{~b}$ & $1.082 \mathrm{~b}$ & $6.277 \mathrm{~b}$ & $0.598 \mathrm{~b}$ & $40.76 \mathrm{~b}$ & $58.62 \mathrm{c}$ & $340.02 \mathrm{c}$ & $0.144 \mathrm{~b}$ & $2878 \mathrm{~b}$ \\
\hline 120N-80P-TAL4 & $5457 \mathrm{~b}$ & $1.104 \mathrm{~b}$ & $6.403 \mathrm{~b}$ & $0.583 \mathrm{~b}$ & $39.48 \mathrm{~b}$ & $60.25 \mathrm{~b}$ & $349.44 \mathrm{~b}$ & $0.143 \mathrm{~b}$ & $2856 \mathrm{~b}$ \\
\hline 120N-80P-SHL70\&TAL4 & $6055 \mathrm{a}$ & $1.263 \mathrm{a}$ & $7.323 \mathrm{a}$ & $0.670 \mathrm{a}$ & $47.44 \mathrm{a}$ & $76.45 \mathrm{a}$ & $443.38 \mathrm{a}$ & $0.153 \mathrm{a}$ & 3056 a \\
\hline Calculated F & $* *$ & $* *$ & ** & ** & $* *$ & ** & $* *$ & $* *$ & ** \\
\hline C.V $(\%)$ & 2.43 & 2.33 & 2.33 & 2.62 & 3.31 & 2.19 & 2.20 & 2.80 & 2.85 \\
\hline No inoculation & $3979 \mathrm{c}$ & $0.851 \mathrm{c}$ & $4.936 \mathrm{c}$ & $0.440 \mathrm{c}$ & $25.96 \mathrm{c}$ & $34.46 \mathrm{c}$ & $199.85 \mathrm{c}$ & $0.117 \mathrm{c}$ & $2331 \mathrm{c}$ \\
\hline SHL70 & $4654 \mathrm{~b}$ & $0.949 \mathrm{~b}$ & $5.506 \mathrm{~b}$ & $0.523 \mathrm{~b}$ & $33.43 \mathrm{~b}$ & $44.82 \mathrm{bc}$ & $259.96 \mathrm{bc}$ & $0.129 b$ & $2580 \mathrm{~b}$ \\
\hline TAL4 & $4668 \mathrm{~b}$ & $0.950 \mathrm{~b}$ & $5.509 \mathrm{~b}$ & $0.516 \mathrm{~b}$ & $32.30 \mathrm{~b}$ & $45.23 \mathrm{~b}$ & $262.35 \mathrm{~b}$ & $0.131 \mathrm{~b}$ & $2627 \mathrm{~b}$ \\
\hline SHL70\&TAL4 & $5387 \mathrm{a}$ & $1.093 \mathrm{a}$ & $6.338 \mathrm{a}$ & $0.596 \mathrm{a}$ & $40.66 \mathrm{a}$ & $59.62 \mathrm{a}$ & $345.82 \mathrm{a}$ & $0.144 \mathrm{a}$ & $2880 \mathrm{a}$ \\
\hline Calculated F & $* *$ & $* *$ & $* *$ & $* *$ & $* *$ & $* *$ & $* *$ & $* *$ & $* *$ \\
\hline C.V $(\%)$ & 17.14 & 12.00 & 12.01 & 11.91 & 18.56 & 27.39 & 27.41 & 8.66 & 8.67 \\
\hline $0 \mathrm{~N}-\mathrm{OP}$ & $3653 \mathrm{c}$ & $0.842 \mathrm{c}$ & $4.882 \mathrm{c}$ & $0.446 \mathrm{c}$ & $25.63 \mathrm{c}$ & $31.14 \mathrm{c}$ & $180.59 \mathrm{c}$ & $0.121 \mathrm{~b}$ & 2412 b \\
\hline $60 \mathrm{~N}-40 \mathrm{P}$ & $4908 \mathrm{~b}$ & $0.941 \mathrm{~b}$ & $5.455 \mathrm{~b}$ & $0.530 \mathrm{~b}$ & $34.25 \mathrm{~b}$ & $46.51 \mathrm{~b}$ & $269.76 \mathrm{~b}$ & $0.126 \mathrm{~b}$ & $2530 \mathrm{~b}$ \\
\hline $120 \mathrm{~N}-80 \mathrm{P}$ & $5455 \mathrm{a}$ & $1.100 \mathrm{a}$ & $6.380 \mathrm{a}$ & $0.580 \mathrm{a}$ & $39.38 \mathrm{a}$ & $60.45 \mathrm{a}$ & $350.63 \mathrm{a}$ & $0.144 \mathrm{a}$ & $2872 \mathrm{a}$ \\
\hline Calculated F & $* *$ & $* *$ & ** & ** & ** & $* *$ & ** & ** & ** \\
\hline C.V $(\%)$ & 11.41 & 9.81 & 9.31 & 11.69 & 16.96 & 20.41 & 20.42 & 8.59 & 8.67 \\
\hline
\end{tabular}

${ }^{+}$Seed yield $=$grain yield $\mathrm{x} 0.81$

Means within a column followed by the same letter/s are not significantly different at $\mathrm{p}<0.05$

*and ** are significantly different at 0.05 and 0.01 probability respectively

Table 7. Effects of endophytic bacteria and chemical fertilizers on P contents of rice straw, rice seed and soil of Tuy An site

\begin{tabular}{|c|c|c|c|c|c|c|c|c|}
\hline Treatment & $\begin{array}{l}\text { Seed rice } \\
\text { Yield } \\
(\mathrm{kg} / \mathrm{ha})^{+}\end{array}$ & $\begin{array}{l}P \text { in seed } \\
\text { rice }(\%)\end{array}$ & $\begin{array}{l}P \text { content } \\
\text { in rice } \\
\text { straw }(\%)\end{array}$ & $\begin{array}{l}\text { Total } P \text { in } \\
\text { rice straw } \\
\text { (kg/ha) }\end{array}$ & $\begin{array}{l}\text { Total } P \text { in } \\
\text { seed rice } \\
(\mathrm{kg} / \mathrm{ha})\end{array}$ & $\begin{array}{l}\text { Total } P \text { in } \\
\text { plant rice } \\
\text { (kg/ha) }\end{array}$ & $\begin{array}{l}\text { P content } \\
\text { In soil } \\
(\mathrm{mg} / \mathrm{kg})\end{array}$ & $\begin{array}{l}\text { Total } P \text { in } \\
\text { soil }(\mathrm{kg} / \mathrm{ha})\end{array}$ \\
\hline ON-OP-No inoculation & $2815 \mathrm{~g}$ & $0.214 \mathrm{f}$ & $0.049 \mathrm{~g}$ & $2.584 \mathrm{f}$ & $5.942 \mathrm{~h}$ & $8.527 \mathrm{i}$ & $4.163 \mathrm{~h}$ & $8.327 \mathrm{~h}$ \\
\hline 0N-0P-SHL70 & $3905 \mathrm{f}$ & $0.231 \mathrm{e}$ & $0.051 \mathrm{~g}$ & $2.837 \mathrm{f}$ & $8.351 \mathrm{~g}$ & $11.188 \mathrm{~h}$ & $5.157 \mathrm{~g}$ & $10.313 \mathrm{~g}$ \\
\hline 0N-OP-TAL4 & $3615 \mathrm{f}$ & $0.263 \mathrm{~cd}$ & $0.052 \mathrm{fg}$ & $2.882 \mathrm{f}$ & $9.475 \mathrm{f}$ & $12.357 \mathrm{~g}$ & $5.510 \mathrm{fg}$ & $11.020 \mathrm{fg}$ \\
\hline 0N-0P-SHL70\&TAL4 & $4577 \mathrm{~d}$ & $0.272 \mathrm{bc}$ & $0.083 \mathrm{c}$ & $5.241 \mathrm{c}$ & $12.423 \mathrm{~d}$ & $17.664 \mathrm{e}$ & 6.427 ef & $12.853 \mathrm{ef}$ \\
\hline 60N-40P-No inoculation & $4232 \mathrm{e}$ & $0.232 \mathrm{e}$ & 0.061 ef & $3.608 \mathrm{e}$ & $9.654 \mathrm{f}$ & $13.261 \mathrm{~g}$ & $6.443 \mathrm{e}$ & $12.887 \mathrm{e}$ \\
\hline 60N-40P-SHL70 & $4941 \mathrm{c}$ & $0.253 \mathrm{~d}$ & $0.068 \mathrm{de}$ & $4.420 \mathrm{~d}$ & $12.545 \mathrm{~d}$ & $16.965 \mathrm{e}$ & $7.483 \mathrm{~d}$ & $14.967 \mathrm{~d}$ \\
\hline 60N-40P-TAL4 & $4931 \mathrm{c}$ & $0.258 \mathrm{~d}$ & $0.071 \mathrm{~d}$ & $4.456 \mathrm{~d}$ & $12.732 \mathrm{~d}$ & $17.188 \mathrm{e}$ & $7.287 \mathrm{de}$ & $14.573 \mathrm{de}$ \\
\hline 60N-40P-SHL70\&TAL4 & $5528 \mathrm{~b}$ & $0.282 \mathrm{~b}$ & $0.093 \mathrm{~b}$ & $6.464 \mathrm{~b}$ & $15.700 \mathrm{~b}$ & $22.164 \mathrm{~b}$ & $8.767 \mathrm{c}$ & $17.533 \mathrm{c}$ \\
\hline $120 \mathrm{~N}-80 \mathrm{P}-\mathrm{No}$ inoculation & $4890 \mathrm{c}$ & $0.240 \mathrm{e}$ & 0.061 ef & $3.849 \mathrm{e}$ & $11.673 \mathrm{e}$ & $15.522 \mathrm{f}$ & $8.483 \mathrm{c}$ & $16.967 \mathrm{c}$ \\
\hline $120 \mathrm{~N}-80 \mathrm{P}-\mathrm{SHL} 70$ & $5417 \mathrm{~b}$ & $0.275 \mathrm{~b}$ & $0.072 \mathrm{~d}$ & $4.931 \mathrm{~cd}$ & $14.910 \mathrm{c}$ & $19.841 \mathrm{~d}$ & $8.700 \mathrm{c}$ & $17.400 \mathrm{c}$ \\
\hline 120N-80P-TAL4 & $5457 \mathrm{~b}$ & $0.263 \mathrm{~cd}$ & $0.094 \mathrm{~b}$ & $6.440 \mathrm{~b}$ & $14.391 \mathrm{c}$ & $20.831 \mathrm{c}$ & $10.633 \mathrm{~b}$ & $21.267 \mathrm{~b}$ \\
\hline 120N-80P-SHL70\&TAL4 & $6055 a$ & $0.299 \mathrm{a}$ & $0.111 \mathrm{a}$ & $7.850 \mathrm{a}$ & $17.977 \mathrm{a}$ & $25.828 \mathrm{a}$ & $13.167 \mathrm{a}$ & $26.333 \mathrm{a}$ \\
\hline Calculated F & $* *$ & $* *$ & $* *$ & $* *$ & $* *$ & $* *$ & $* *$ & $* *$ \\
\hline C.V $(\%)$ & 2.43 & 2.57 & 7.22 & 7.00 & 3.32 & 3.41 & 7.14 & 7.13 \\
\hline No inoculation & $3979 \mathrm{c}$ & $0.228 \mathrm{c}$ & $0.057 \mathrm{c}$ & $3.347 \mathrm{c}$ & $9.090 \mathrm{c}$ & $12.437 \mathrm{c}$ & $6.363 \mathrm{~b}$ & $12.727 \mathrm{~b}$ \\
\hline SHL70 & $4654 \mathrm{~b}$ & $0.253 \mathrm{~b}$ & $0.063 \mathrm{bc}$ & $4.063 \mathrm{bc}$ & $11.936 \mathrm{~b}$ & $15.998 \mathrm{~b}$ & $7.113 b$ & $14.227 \mathrm{~b}$ \\
\hline TAL4 & $4668 \mathrm{~b}$ & $0.262 \mathrm{~b}$ & $0.072 \mathrm{~b}$ & $4.592 \mathrm{~b}$ & $12.200 \mathrm{~b}$ & $16.792 \mathrm{~b}$ & $7.810 \mathrm{ab}$ & $15.620 \mathrm{ab}$ \\
\hline SHL70\&TAL4 & 5387 a & $0.284 \mathrm{a}$ & $0.095 \mathrm{a}$ & $6.518 \mathrm{a}$ & $15.367 \mathrm{a}$ & $21.885 \mathrm{a}$ & $9.453 \mathrm{a}$ & $18.907 \mathrm{a}$ \\
\hline Calculated F & $* *$ & $* *$ & $* *$ & $* *$ & $* *$ & $* *$ & $*$ & * \\
\hline C.V $(\%)$ & 17.14 & 5.42 & 18.37 & 24.68 & 20.84 & 21.32 & 29.59 & 29.60 \\
\hline ON-OP & $3653 \mathrm{c}$ & $0.245 \mathrm{~b}$ & $0.059 \mathrm{~b}$ & $3.386 \mathrm{~b}$ & $9.048 \mathrm{c}$ & $12.434 \mathrm{c}$ & $5.314 \mathrm{c}$ & $10.628 \mathrm{c}$ \\
\hline $60 \mathrm{~N}-40 \mathrm{P}$ & $4908 \mathrm{~b}$ & $0.256 \mathrm{ab}$ & $0.073 \mathrm{a}$ & $4.737 \mathrm{a}$ & $12.658 \mathrm{~b}$ & $17.395 \mathrm{~b}$ & $7.495 \mathrm{~b}$ & $14.990 \mathrm{~b}$ \\
\hline $120 \mathrm{~N}-80 \mathrm{P}$ & $5455 \mathrm{a}$ & $0.269 \mathrm{a}$ & $0.048 \mathrm{a}$ & $5.767 \mathrm{a}$ & $14.738 \mathrm{a}$ & $20.506 \mathrm{a}$ & $10.264 \mathrm{a}$ & $20.492 \mathrm{a}$ \\
\hline Calculated F & $* *$ & $* *$ & $* *$ & $* *$ & $* *$ & $* *$ & $* *$ & $* *$ \\
\hline C.V $(\%)$ & 11.41 & 8.86 & 23.20 & 28.49 & 19.45 & 21.32 & 18.40 & 18.39 \\
\hline
\end{tabular}


This showed that $\mathrm{N}$ content in seed rice was important and regression equation as follows:

$$
\mathrm{Y}=-5.124+1.262 \mathrm{X} 1+0.542 \mathrm{X} 2
$$

$\mathrm{Y}=\mathrm{P}$ content in soil, $\mathrm{X} 1=\mathrm{P}$ content in seed rice and $\mathrm{X} 2=\mathrm{P}$ content in straw rice $\left(\mathrm{R}^{2}=0.973\right)$

This showed that $\mathrm{P}$ content in seed rice was important and regression equation as follows:

$$
\mathrm{Y}=1812.44+17.37 \mathrm{X} 1-0.23 \mathrm{X} 2
$$

$\mathrm{Y}=\mathrm{N}$ content in soil, $\mathrm{X} 1=\mathrm{N}$ content in seed rice and $\mathrm{X} 2=$ $\mathrm{N}$ content in straw rice $\left(\mathrm{R}^{2}=0.832\right)$

This showed that $\mathrm{N}$ content in seed rice was important with regression equation as follows:

$$
\mathrm{Y}=0.291+0.728 \mathrm{X} 1+1.345 \mathrm{X} 2
$$

$\mathrm{Y}=\mathrm{P}$ content in soil, $\mathrm{X} 1=\mathrm{P}$ content in seed rice and $\mathrm{X} 2=\mathrm{P}$ content in straw rice $(\mathrm{R} 2=0.851)$

This showed that $\mathrm{P}$ content in straw rice controbuted remarbly

The highest grain yield in $120 \mathrm{~N} 80 \mathrm{P}$ plus inoculation (both strains) treatment and grain yield of $60 \mathrm{~N}-40 \mathrm{P}$ plus inoculation with SHL70 strain treatment did not differ with grain yield of $120 \mathrm{~N} 80 \mathrm{P}$ without inoculation, therefore inoculation reduced or saved $50 \% \mathrm{~N}$ and P fertilizers (60N40P) in Dong Hoa site and Tuy An site. Application of the mixtute of two strains in rice cultivation increased $87.06 \mathrm{~kg} / \mathrm{ha}$ protein and 125.64 $\mathrm{kg} / \mathrm{ha}$ protein in seed rice in comparison to control (without inoculation) at Dong Hoa site and Tuy An site, respectively. Applying $120 \mathrm{~kg} \mathrm{~N}+80 \mathrm{~kg} \mathrm{P}_{2} \mathrm{O}_{5} /$ ha plus inoculation (both strains) enhanced $145.70 \mathrm{~kg} / \mathrm{ha}$ and $318.67 \mathrm{~kg} / \mathrm{ha}$ protein in seed rice in comparison with control (without inoculation) at Dong Hoa and Tuy An site, respectively (Table 2 and Figure 3)(Table 3 and Figure 5).

When analysis of $\mathrm{N}$ and $\mathrm{P}$ content in seed rice and straw rice showed that $\mathrm{N}$ and $\mathrm{P}$ accumulation in rice plant (seed and straw) of mixture of two bacterial strains treatment were higher than $\mathrm{N}$ and $\mathrm{P}$ content in rice plant of $120 \mathrm{~N}-80 \mathrm{P}$ without inoculation, this demonstrated that the high effectiveness of both strains contributed in the accumulation of $\mathrm{N}$ and $\mathrm{P}$ in rice plant and in cultivated soil in comparison to rice only applying chemical nitrogen and phosphorus without inoculation (Table $4,5,6,7)$. Besides, with $0 \mathrm{~N}-0 \mathrm{P}$ rice plants were inoculated with two strains before planting increased $15.01 \mathrm{~kg} \mathrm{~N}$ from seed rice, $13.950 \mathrm{~kg} \mathrm{~N} / \mathrm{ha}$ from straw rice, $915 \mathrm{~kg} \mathrm{~N} / \mathrm{ha}$ from biological nitrogen fixation, $3.286 \mathrm{~kg} \mathrm{P} / \mathrm{ha}$ from seed rice, $2.534 \mathrm{~kg} \mathrm{P} / \mathrm{ha}$ from straw rice, $5.433 \mathrm{~kg} \mathrm{P} / \mathrm{ha}(12.55 \mathrm{~kg}$ $\mathrm{P}_{2} \mathrm{O}_{5} / \mathrm{ha}$ ) in soil with total $\mathrm{P}$ was $11.253 \mathrm{~kg} \mathrm{P} / \mathrm{ha}$ from phosphate solubilization and $21.662 \mathrm{~kg} \mathrm{~N} / \mathrm{ha}$ from seed rice, $14.255 \mathrm{~kg} \mathrm{~N} / \mathrm{ha}$ from straw rice, $659 \mathrm{~kg} \mathrm{~N} / \mathrm{ha}$ from biological nitrogen fixation, $6.481 \mathrm{~kg} \mathrm{P}$ from seed rice, $2.657 \mathrm{~kg} \mathrm{P} / \mathrm{ha}$ from straw rice, $4.526 \mathrm{~kg} \mathrm{P} / \mathrm{ha}\left(10.455 \mathrm{~kg} \mathrm{P}_{2} \mathrm{O}_{5} / \mathrm{ha}\right)$ in soil with total $\mathrm{P}$ was $13.664 \mathrm{~kg} \mathrm{P} / \mathrm{ha}$ from phosphate solubilization at Dong Hoa site and Tuy An site, respectively. Therefore, application of endophytic bacterial strains in rice cultivation increased soil fertility in both sites but soil fertility at Dong Hoa site was higher than Tuy An site perhaps high soil fertility at Dong Hoa site.

Rice is the world's most important food crop and a primary source of food for more than half the world's population. More than $90 \%$ of rice is grown and consumed in Asia where $60 \%$ of the people on earth live [12]. In accordance to Ladha and Reddy [13], nitrogen is the major limiting nutrient for rice production. Nitrogen is used to synthesize plant proteins and nucleic acids, including DNA. Response of rice varieties, especially high-yielding rice, to $\mathrm{N}$ is generally recognized, but crop recovery of applied $\mathrm{N}$ is only $50 \%$ due to the losses in several ways. In this context, biological $\mathrm{N}_{2}$ fixation (BNF) has been considered an alternative, which may prove to be a better solution to supply nitrogen to the cropping systems of the future [14]. It is widely recognized that BNF can benefit the rice crop [12]. However, rice production is largely limited by soil phosphorus $(\mathrm{P})$ deficiencies in many parts of the world [15][2].

Especially the use of nitrogen fertilizer is of great importance in rice production [3] and $\mathrm{N}_{2}$ fixation is a prime requisite for plant growth particularly in crops like rice. The results of Rodrigues et al. [12] inoculation of strains of Azospirillum amazonense increased grain dry matter accumulation, the number of panicles and nitrogen accumulation at grain maturation, especially BNF contributed up to $27 \%$.

With grain yield from 5 to 8 tons/ha, rice plant required 60 to $100 \mathrm{~kg} \mathrm{~N} / \mathrm{ha}$ [16] and biological nitrogen only provided 50 $\mathrm{kg} \mathrm{N} / \mathrm{ha}$ [17]. Therefore using biofertilizer for rice cultivation contributed approx 50\% $\mathrm{N}$ quantity and it improved soil fertility through phosphate solubilization, IAA biosynthesis [18]. Many endophytic bacterial strains were isolated and identified in soil and rice plant in the Mekong Delta as Azospirillum lipoferum [19], Burkholderia vietnamiensis [20][21] with good characteristics as high nitrogen fixation, phosphate solubilization and IAA biosynthesis. They have been used in biofertilizer for rice production [22][23].

Azospirillum amazonense SHL70 and Burkholderia kururiensis PHL87 were isolated fron rice cultivated on soil of Phu Yen province, Vietnam [8][9] and using two strains as biofertilizer for rice cultivation on sandy loam soil effectively. Oliveira et al. [24] application of Azospirilum amazonense and Burkholderia sp., increased rice biomass to $39 \%$ in comparison to control (without inoculation) in pot experiment (Brasil).

\section{Conclusion}

Using the mixture of Azospirillum amazonense and Bacillus subtilis increased grain yield and improvement of quality seed rice and soil fertility of cultivated sandy loam soil of Phu Yen province, Vietnam. Application of two bacterial strains in rice plant before transplanting save $50 \% \mathrm{~N}$ and $\mathrm{P}$ fertiizers $(60 \mathrm{~kg}$ $\mathrm{N}$ and $40 \mathrm{~kg} \mathrm{P}_{2} \mathrm{O}_{5} / \mathrm{ha}$ ) and the highest grain yield in applying $120-80 \mathrm{P}_{2} \mathrm{O}_{5} /$ ha and inoculated with two strains treatment. 


\section{References}

[1] I. Kogrl-Knabner, W. Amelung, Z.H. Cao, S. Fiedler, P. Frenzel and R. Zahn, "Biogeochemistry of paddy soils," Geoderma., vol. 157, pp. 1-14, 2010.

[2] N.H. Fageria, A.B. Santos, and A.B. Heinemann, "Lowland rice genotypes evaluation for phosphorus use efficiency in tropical lowland,” J. Plant Nutr., vol. 34, pp:1087-1095, 2011.

[3] S.H. Jia, M.B. Gururanib and S.C. Chuna,'Isolation and characterization of plant growth endophytic diazotrophic bacteria from Korea cultivars," Microbiol. Res., vol. 169, pp:83-98, 2014.

[4] B. Yang, H. Ma, X. Wang, Y. Jia, J. Hu, X. Li and C. Dai, "Improvement of nitrogen accumulation and metabolosim in rice (Oryza sativa L.) by the endophyte Phomopsis liquidambari," Plant Physiology and Biochemistry, vol. 82, pp:172-182, 2014.

[5] B. Bhardwaj, M. W. Ansan, R. K. Sahoo and N. Tuteja, "Biofertilizers function as key player in sustainble agriculture by improving soil fertility, plant tolerant and crop productivity," Microbial Cell Factories, vol. 13, pp: 2-10, 2014.

[6] J.N. Galloway, A.R. Townsend, J.W. Erisman, M. Bekund, Z.C. Cai, J.B. Frency, L.A. Martinelli, S.P. Seizinger, and M.A Sutton, "Transformation of the nitrogen cycle: recent trends, questions and potential solutions," Science, vol. 320, pp.889-892, 2008.

[7] R. J..Diaz and R. Rosenberg, "Spreading dead zones and consequences for marine ecosystems," Science, vol. 321, pp: 926-929, 2008.

[8] V. T. P. Nhu and C. N. Diep, "Isolation, characterization and phylogenetic analysis of endophytic bacteria in rice plant cultivated on soil of Phu Yen province, Vietnam," American Journal of Life Sciences. Vol. 2, No. 3, 2014a, 117-127. doi: 10.11648/j.ajls.20140202.18 (online). ISSN 2328 - 5737

[9] V.T.P. Nhu and C.N. Diep, "Effects of Azospirillum amazonense and Burkholderia kururiensis on high-yielding rice (cv. Ma Lam 213) cultivated on sandy loam soil of Tuy Hoa city, Phu Yen province," Science J. of Can Tho University, Vietnam, vol. 33b, pp: 85-96, 2014b.

[10] M. Park, C. Kim. H.S. Yang, H.S. Lee, W. Shin, S. Kim and K. Tongminsa, "Isolation and characteration of diazotrophic growth promotion bacteria from Rhizophere of agricultural crops of Korea," Microbiological Research, vol. 160, pp: 127-133, 2005.

[11] C.S. Nautiyal, "An efficient microbiological growth medium for screening phosphate-solubilizing microorganisms," FEMS Microbiology Letters, vol. 170, pp: 256-270, 1999.

[12] E. P. Rodrigues, L. S. Rodrigues, A. L. M. de Olivera, V. L. D. Baldani, K. R. S. Teixeira, S. Urquiaga and V. M. Reis, "Azospirillum amazonense inoculation: effects on growth, yield and $\mathrm{N}_{2}$ fixation of rice (Oryza sativa $\mathrm{L}$.)," Plant Soil, vol. 302, pp: 249-261, 2008.

[13] J.K. Ladha and P.M. Reddy, "Nitrogen fixation in rice ecosystem: state of knowledge and futrure prospects," Plant Soil, vol.252, pp.151-167, 2003.

[14] E. S. Jensen and H. H. Nielsen, "How can increased use of biological $\mathrm{N}_{2}$ fixation in agriculture benefit the environment?," Plant Soil, vol. 252, pp: 177-186, 2003.

[15] K.G. Raghothama, "Phosphate acquisition," Annu. Rev. Plant Biol., vol. 50, pp: 665-693, 1999.

[16] S.E. Fischer, M.J. Miguel and G. B. Mori,"Effect of root exudates on the exopolysaccharide composition and the lipopolysaccharide prolife of Azospirillum brasilense $\mathrm{Cd}$ under saline stress," FEMS Microbiol. Lett., vol. 219, pp: 53-62, 2003.

[17] Roger, P. A and J. K. Ladha, "Biological N, fixation in wetland rice fields: Estimation and contribution to nitrogen," Plant Soil, vol. 141, pp: 41-55, 1992.

[18] J.K. Ladha, G.J.D. Kirk, J. Bennett, C.K. Reddy, and U. Singh, "Oppornitunities for increased nitrogen use efficiency from improved lowland rice germplasm," Field Crops Res., vol. 50, pp: 36-69, 1998.

[19] C. N. Diep, P. T. K. Van and L. N. Dau, "Detection of Endophytic Azospirillum lipoferum in local rice cultuvars (Oryza sativa L.) cultivated in the Mekong Delta, Vietnam. Proceedings of National Conference of Life Science organized at University of Qui Nhon, pp. 456-459, Science-Technology Publising House, Ha Noi, 2007.

[20] T. V. Van, P. Mavingui, O. Berge and T. Heulin, "Promotion de croissance du riz incocule par une bacteria fixatrice dazote, Burkhoderia vietnamensis, isolated in soil acid Viet Nam, Agronomie, vol.14, pp: 697 -707, 1994.

[21] L. M. Gillis, T.V. Van, R. Bardin, M. Mart, P. Hebbar and A. Willems, "Polyphasic taxonomy in the genus Burkholderia leading to an emended description of the genus and proposition of Burkholderiu vietnamiensis sp. nov. for $\mathrm{N}_{2}$-fixing isolates from rice in Vietnam. Int. Nal of Syst. Cteriologayp, vol. 45, pp: 274-289, 1995.

[22] N. Dau, N. T. X. My, and C. N. Diep, "Nitrogen fixation, Phosphate Solubilization and IAA biosynthesis of Endophytic Azospirillum lipoferum. Proceedings of National Conference of Life Science organized at University of Qui Nhon, pp.445-448, 2007. Science-Technology Publising House, Ha Noi

[23] C. N. Diep,'Effect of biofertilizer on High-yielding Rice Cultivated on Alluvial Soil of Mekong Delta," Proceedings of JSPS AA International Seminar Can Tho University, Vietnam, September 2010, pp: 18-24. 2010.

[24] Oliveira, A. L.M., S. Urquiaga, J. Döbereiner and I. J. Baldani, "The effect of inoculating endophytic $\mathrm{N}_{2}$-fixing bacteria on micropropagated sugarcane plants. Plant Soil, vol. 242, pp: 205-215, 2003. 